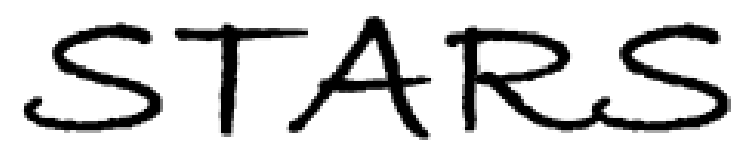

University of Central Florida

STARS

$1-1-2010$

\title{
Sexual Signal Evolution Outpaces Ecological Divergence during Electric Fish Species Radiation
}

\author{
Matthew E. Arnegard \\ Peter B. Mclntyre \\ Luke J. Harmon \\ Miriam L. Zelditch \\ William G. R. Crampton \\ University of Central Florida
}

See next page for additional authors

Find similar works at: https://stars.library.ucf.edu/facultybib2010

University of Central Florida Libraries http://library.ucf.edu

This Article is brought to you for free and open access by the Faculty Bibliography at STARS. It has been accepted for inclusion in Faculty Bibliography 2010 s by an authorized administrator of STARS. For more information, please contactSTARS@ucf.edu.

\section{Recommended Citation}

Arnegard, Matthew E.; McIntyre, Peter B.; Harmon, Luke J.; Zelditch, Miriam L.; Crampton, William G. R.; Davis, Justin K.; Sullivan, John P.; Lavoué, Sébastien; and Hopkins, Carl D., "Sexual Signal Evolution Outpaces Ecological Divergence during Electric Fish Species Radiation" (2010). Faculty Bibliography 2010s. 6957.

https://stars.library.ucf.edu/facultybib2010/6957

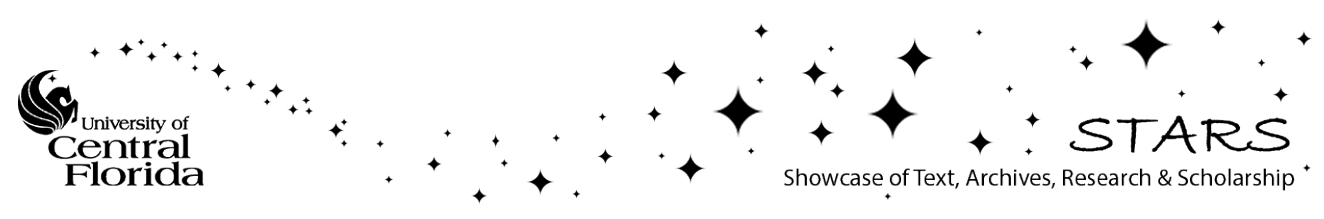


Authors

Matthew E. Arnegard, Peter B. McIntyre, Luke J. Harmon, Miriam L. Zelditch, William G. R. Crampton, Justin K. Davis, John P. Sullivan, Sébastien Lavoué, and Carl D. Hopkins 


\title{
Sexual Signal Evolution Outpaces Ecological Divergence during Electric Fish Species Radiation
}

\author{
Matthew E. Arnegard, ${ }^{1, \star}$ Peter B. McIntyre, ${ }^{2}$ Luke J. Harmon, ${ }^{3}$ Miriam L. Zelditch, ${ }^{4}$ \\ William G. R. Crampton, ${ }^{5}$ Justin K. Davis, ${ }^{6}$ John P. Sullivan, ${ }^{7}$ Sébastien Lavoué, ${ }^{8}$ and \\ Carl D. Hopkins ${ }^{9}$
}

1. Department of Zoology, University of British Columbia, Vancouver, British Columbia V6T 1Z4, Canada; 2. Center for Limnology, University of Wisconsin, Madison, Wisconsin 53706; 3. Department of Biological Sciences, University of Idaho, Moscow, Idaho 83844; 4. Museum of Paleontology, University of Michigan, Ann Arbor, Michigan 48109; 5. Department of Biology, University of Central Florida, Orlando, Florida 32816; 6. Department of Mathematics, University of Central Florida, Orlando, Florida 32816; 7. Cornell University Museum of Vertebrates, Ithaca, New York 14850; 8. Department of Zoology, Natural History Museum, London SW7 5BD, United Kingdom; 9. Department of Neurobiology and Behavior, Cornell University, Ithaca, New York 14853

Submitted January 28, 2010; Accepted May 17, 2010; Electronically published July 23, 2010

Online enhancements: appendixes.

A BSTRACT: Natural selection arising from resource competition and environmental heterogeneity can drive adaptive radiation. Ecological opportunity facilitates this process, resulting in rapid divergence of ecological traits in many celebrated radiations. In other cases, sexual selection is thought to fuel divergence in mating signals ahead of ecological divergence. Comparing divergence rates between naturally and sexually selected traits can offer insights into processes underlying species radiations, but to date such comparisons have been largely qualitative. Here, we quantitatively compare divergence rates for four traits in African mormyrid fishes, which use an electrical communication system with few extrinsic constraints on divergence. We demonstrate rapid signal evolution in the Paramormyrops species flock compared to divergence in morphology, size, and trophic ecology. This disparity in the tempo of trait evolution suggests that sexual selection is an important early driver of species radiation in these mormyrids. We also found slight divergence in ecological traits among closely related species, consistent with a supporting role for natural selection in Paramormyrops diversification. Our results highlight the potential for sexual selection to drive explosive signal divergence when innovations in communication open new opportunities in signal space, suggesting that opportunity can catalyze species radiations through sexual selection, as well as natural selection.

Keywords: speciation, sexual selection, key innovation, private communication channel, electric organ discharge.

\footnotetext{
* Corresponding author. Present address: Division of Human Biology, Fred Hutchinson Cancer Research Center, Seattle, Washington 98109; e-mail: arnegard@zoology.ubc.ca.

Am. Nat. 2010. Vol. 176, pp. 335-356. (c) 2010 by The University of Chicago. 0003-0147/2010/17603-51892\$15.00. All rights reserved.

DOI: $10.1086 / 655221$
}

\section{Introduction}

Rapid species radiations have given rise to much of Earth's biodiversity. Divergent or disruptive natural selection on ecological traits, such as body size, shape, trophic ecology, and habitat use, is believed to be the primary causal factor in many celebrated examples of adaptive radiation (Losos et al. 1998; Schluter 2000; Lovette et al. 2002; Grant and Grant 2008). In such cases, sexual signals and other components of prezygotic isolation may remain unchanged or diverge only after differentiation in ecological traits begins (Streelman and Danley 2003). Rates of ecomorphological divergence and speciation are enhanced by ecological opportunities (Parent and Crespi 2009), which may arise as a result of the origin of novel ecological traits or key innovations (Simpson 1953; Schluter 2000).

In contrast, dramatic divergence of courtship signals in other model radiations has encouraged suggestions that sexual selection takes precedence in driving diversification (Masta and Maddison 2002; Allender et al. 2003; Mendelson and Shaw 2005; Elias et al. 2006a; Boul et al. 2007). In studies of signal variation in many animal radiations, it has been difficult to adequately quantify all relevant aspects of signal structure (Allender et al. 2003; Price et al. 2007; Ritchie 2007; Seehausen et al. 2008). This, in turn, hinders assessment and comparison of rates of phenotypic evolution (Lerman 1965; Gingerich 1993; Hendry and Kinnison 1999). Additionally, environmental effects on signal transmission or reception often constrain signal evolution by sexual selection (Bradbury and Vehrencamp 1998; Gerhardt 1999). In cases of sensory drive (Endler 1992), it may be difficult to separate the effects of natural and sexual selection because these influences are intimately 
intertwined during the process of divergence (Seehausen et al. 2008). Moreover, courtship traits that govern attractiveness to mates may be subjected simultaneously to natural selection mediated by resource competition or predation and to sexual selection mediated by mate attraction (Rundle et al. 2000; Podos 2001; Kingston and Rossiter 2004; Podos and Hendry 2006). This interplay between signal evolution and ecological fitness complicates efforts to compare the relative importance of natural and sexual selection.

Distinguishing the general roles of natural and sexual selection during a species radiation requires a study group in which ecological traits and courtship signals evolve largely independently, can be quantitatively described, and can be placed in a phylogenetic context across many radiating species. If sexual selection on a signaling trait is more important in driving the radiation of such a group than is natural selection on any ecological trait, the signaling trait should evolve more rapidly than any of the ecological traits (Ritchie 2007). If natural selection due to species interactions or environmental influences is more important, one or more ecological traits should exhibit more rapid divergence than the courtship signals.

Mormyrid electric fishes of Africa offer an ideal combination of high species diversity and quantifiable courtship signals that are not closely tied to ecological selection pressures, enabling assessment of the relative importance of sexual and natural selection during their diversification. All mormyrids produce and sense courtship signals in the form of weak electric organ discharges (EODs). This innovative signaling modality is made possible by a novel class of tuberous electroreceptors used for communication and by the mormyroid electric organ (Bass 1986a; Zakon 1988; Caputi et al. 2005; Kawasaki 2005). Mormyrids communicate by sending and receiving EODs between individuals (Hopkins 1986; Moller 1995). Because EODs are relatively simple signals (fig. $1 A$ ), they are well described using continuous measures of waveform variation (Arnegard and Hopkins 2003; Crampton et al. 2008). By comparison, visual and chemical signals are generally more difficult to quantify along continuous trait axes.

The electrosensory modality is the primary communication channel for mormyrid sexual signaling, enabling reduced eye development and nocturnal activity (Moller 1995; von der Emde et al. 1998; Arnegard and Carlson 2005). EODs vary across species (fig. 1A), and they are often dramatically sexually dimorphic (Hopkins and Bass 1981; Bass and Hopkins 1983; Bass 1986a; Moller 1995). Experimental studies have shown that both males and females exhibit mating preferences for quantifiable features of EOD waveforms (Hopkins and Bass 1981; Arnegard et al. 2006; Machnik and Kramer 2008; Feulner et al. 2009a), enabling sexual selection on these signals. Though mor- myrids orient to their environment and detect prey by sensing distortions in their self-generated electric fields (von der Emde et al. 1998; Arnegard and Carlson 2005), there is no evidence that EOD waveform divergence is driven by ecological selection due to resource competition (see app. A in the online edition of the American Naturalist). Conspecific males and females electrolocate objects in the same habitats, despite large sexually dimorphic differences in signal structure. In contrast to EODs, morphology has been linked to ecological divergence in mormyrids (Marrero and Winemiller 1993; Winemiller and Adite 1997). However, body shape and size are probably not the primary cues for mate choice in nocturnally active mormyrids, unlike the case with diurnally active, visually orienting fishes with numerous visually guided predators (e.g., Rundle et al. 2000; McKinnon et al. 2004). Thus, ecological traits and sexual signals appear to be largely independent of one another in mormyrids.

Electrical communication in African rivers is relatively free from extrinsic constraints on signal divergence because of the privacy of this channel (Hopkins 1986) compared to other modes of communication. High-frequency electroreceptors are relatively rare among vertebrates and invertebrates (Hopkins 2010). Mormyroid fishes possess such receptors and are the only animals in Africa that communicate using a relatively high-frequency electrical channel. It has been proposed that electric eels and other electrosensory predators have acted as diversifying selective influences on South American electric fishes (Stoddard 1999). Our study area, the Ivindo River of west-central Africa (fig. 2), lacks electrosensory predators that could have selected for divergence among the high-frequency features distinguishing the majority of mormyrid EODs. For example, the electrosensory mormyroid piscivores Gymnarchus niloticus and Mormyrops anguilloides are absent from the Ivindo (Hopkins et al. 2007), and catfishes (in this region and elsewhere) are insensitive to high electrical frequencies (Zakon 1988; Hanika and Kramer 2000). The flow velocity, $\mathrm{pH}$, dissolved oxygen content, color, and turbidity of water in the Ivindo have no affect on EOD transmission (Hopkins 1986). In addition, fluctuations in water conductivity between dry and rainy seasons in the Ivindo basin are too small to have meaningful effects on signal transmission or impedance matching to environmental conductivity (Bell et al. 1976; Baier 2008). By comparison, acoustic and visual channels are often crowded with many more species of competing signalers, experience substantial environmental effects during transmission, and are received by numerous predatory eavesdroppers, all of which constrain the availability of open signal space (Bradbury and Vehrencamp 1998; Gerhardt 1999). Some important constraints on electric signaling have certainly affected the broader evolution of commu- 


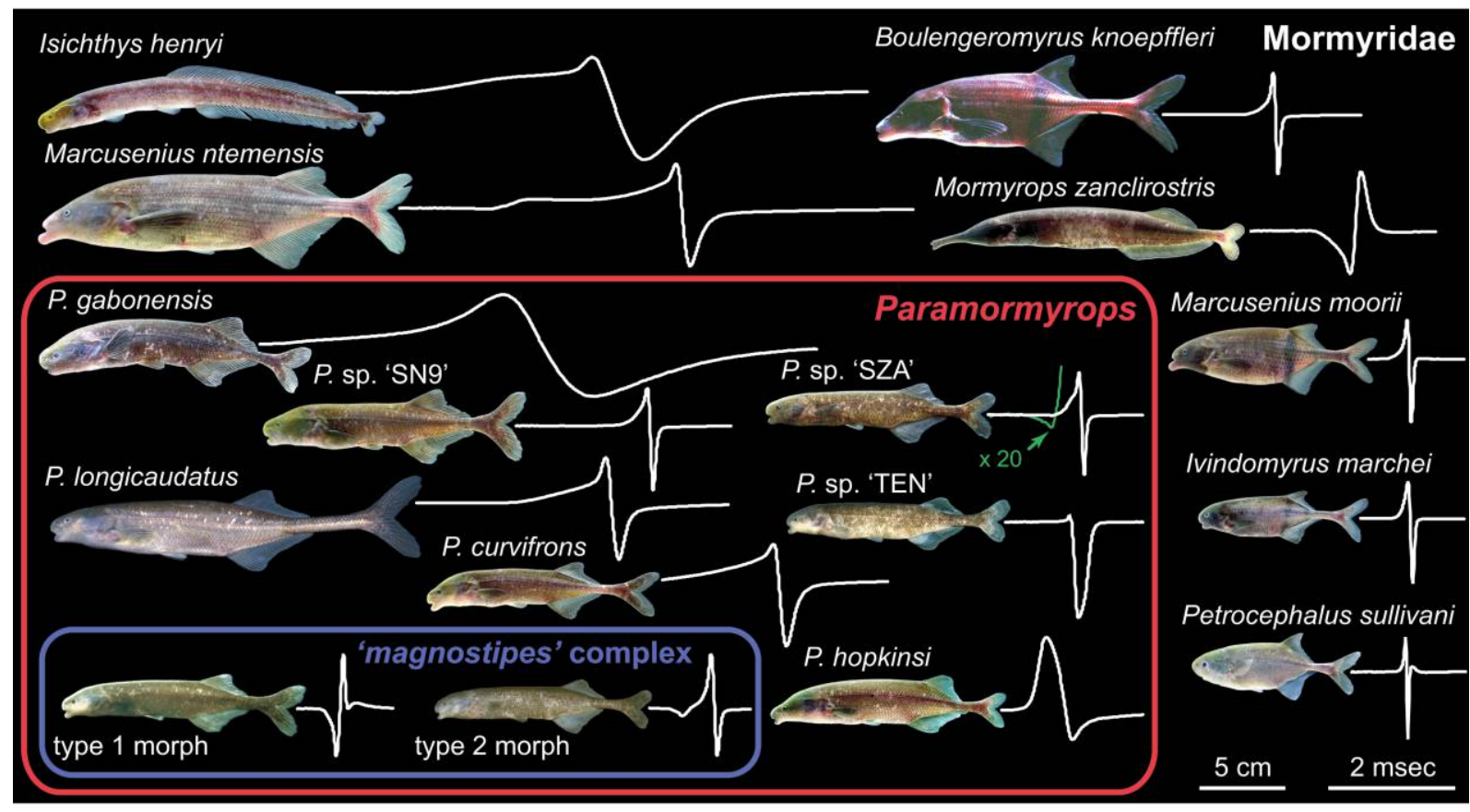

B

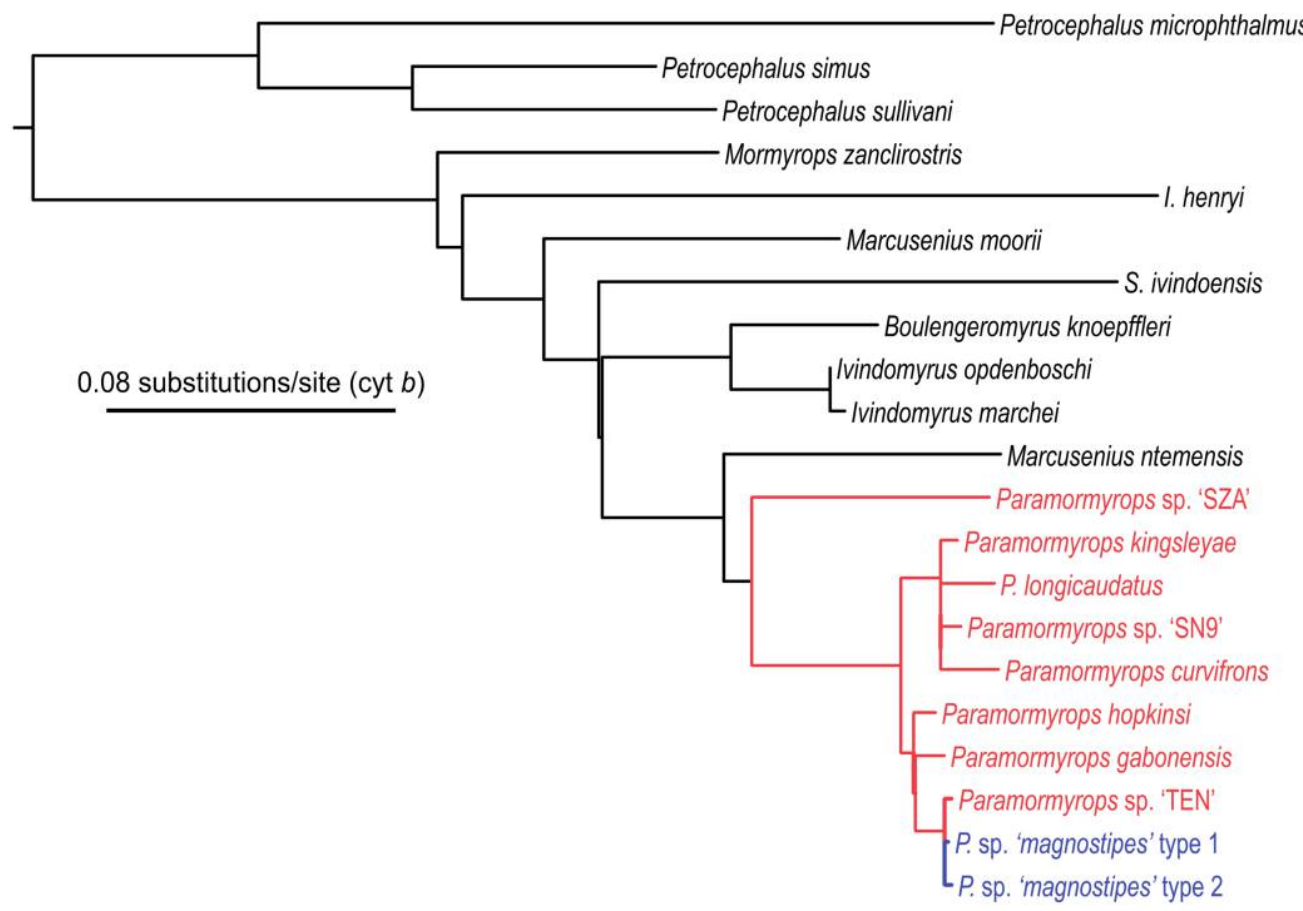

Figure 1: Sympatric mormyrids and their phylogenetic relationships. A, Representative taxa from Loa Loa Rapids at three nested levels of phylogenetic relatedness: two morphs of the magnostipes complex (blue), nine members of the Paramormyrops species flock (red), and species in other mormyrid lineages (outside red box). All photographs are of Loa Loa specimens and are shown on the same size scale (bar $=5 \mathrm{~cm}$ ). Amplitude-normalized electric organ discharges (white voltage traces) are plotted head-positive-up on the same timescale (bar $=2 \mathrm{~ms}$ ). $B$, Phylogenetic tree of Ivindo River mormyrids. The tree topology was inferred from previously published results (app. B in the online edition of the American Naturalist), and maximum likelihood branch lengths were calculated from cytochrome $b$ sequences. Gymnarchus niloticus (not shown) was used as the outgroup taxon. 


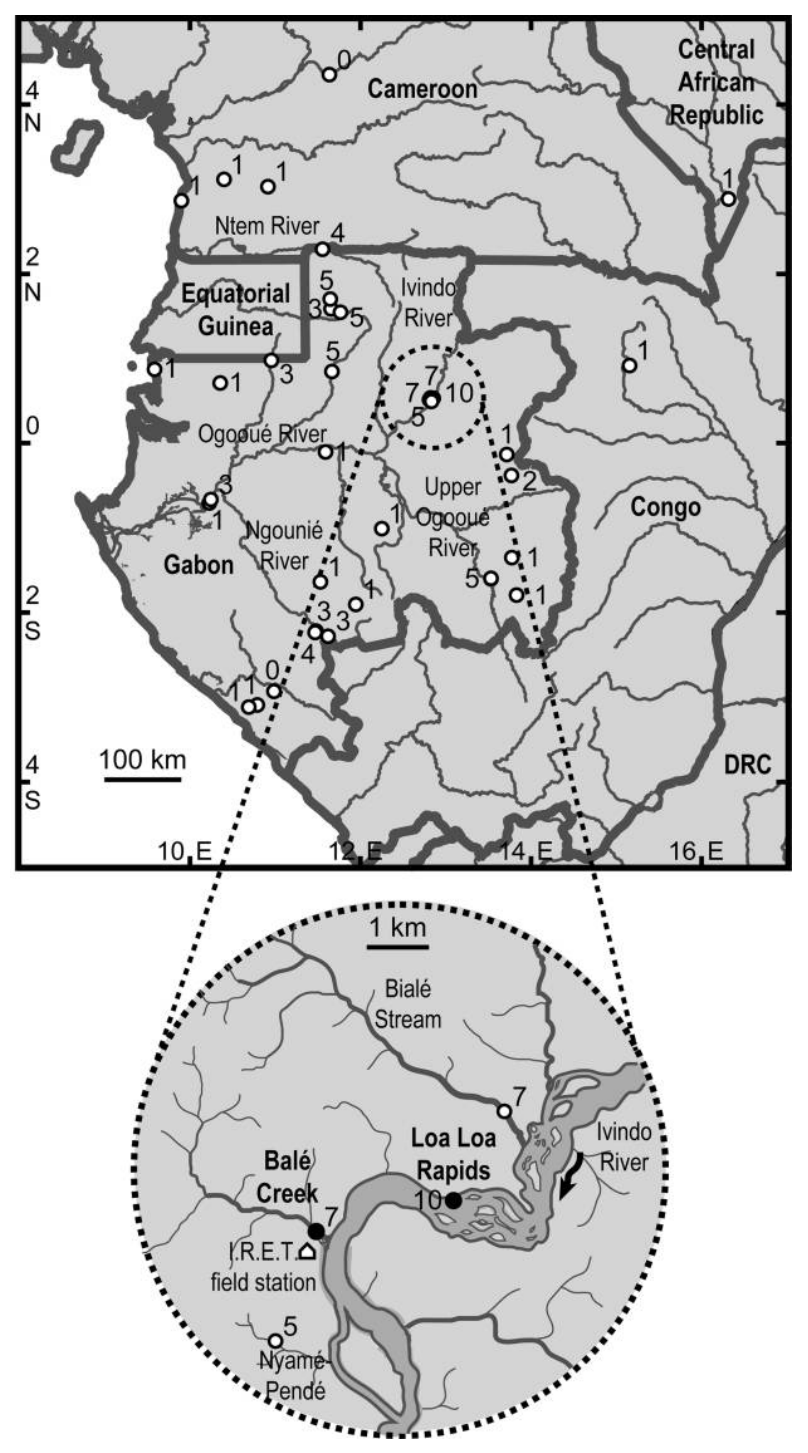

Figure 2: Distribution of Paramormyrops species richness in west-central Africa. Only the best-sampled sites are mapped (i.e., sites at which multiple collections were made between 1998 and 2009). The number of sympatric Paramormyrops species is given for each collection point, conservatively counting the two sympatric morphs of the magnostipes complex as one species wherever one or both morphs co-occur. Paramormyrops is largely restricted to the area between and including the greater Ogooué River basin and the Ntem River. Diversity declines to zero or one sympatric species outside this area. The region of highest-known Paramormyrops diversity occurs within the Ivindo branch of the Ogooue River system. Inset, two mormyrid communities (filled circles) at which rates of trait divergence were measured and compared for the present investigation.

nication in weakly electric fishes (Hopkins 1973, 1980, $1986,1999)$. The key point here is that microevolutionary divergence in signal structure among many closely related mormyrids - particularly in Paramormyrops (Arnegard et al. 2006) —is constrained by relatively few factors compared to other communication modalities.

To quantify the outcomes of sexual and natural selection during species radiation, we measured variation in electrical courtship signals (EODs) among 21 mormyrid species and morphs (table B1 in the online edition of the American Naturalist). We used discrete wavelet analysis to capture timing and frequency variation in EODs (Crampton et al. 2008), both of which are relevant to the electrosensory mechanism underlying sexual selection on these signals (Hopkins and Bass 1981; Xu-Friedman and Hopkins 1999; Arnegard et al. 2006). We also measured variation in three ecological traits that exhibit rapid divergence by natural selection in several well-studied models of adaptive radiation: body size, body shape, and trophic ecology (Schluter 2000; Grant and Grant 2008; Losos 2009; Matthews et al. 2010). Known as elephantfish, mormyrids are renowned for their unusual and diverse morphologies. We quantified this variation (both body shape and body size) by using geometric morphometrics. The trophic roles of mormyrid species were described using stable isotopes of carbon and nitrogen. We focused particular attention on the Paramormyrops species flock (fig. 1, red, blue) because it is the most extensive mormyrid species radiation known (Sullivan et al. 2002, 2004). The Ivindo River is the center of Paramormyrops diversification (fig. 2) and also harbors an electric fish fauna containing a large number of more distantly related mormyrids (fig. 1). We replicated all measurements and analyses using mormyrid assemblages at two distinct sites in the Ivindo basin, a small rainforest stream (Balé Creek) and a set of rapids along the main river channel (Loa Loa). Mormyrid communities at these sites encompass half of all known Paramormyrops species (Lavoué et al. 2008b; see also app. A).

Here, we directly compare rates of divergence between electric signals and each of the ecological traits to estimate the relative roles of sexual and natural selection to species radiation when extrinsic constraints on courtship signal divergence are minimal. Using a phylogenetic framework, we demonstrate that electric signals diverge much more rapidly than all measured ecological traits. We then discuss the implications of this dramatic rate disparity for understanding mechanisms of speciation in mormyrids, as well as the general role of opportunity during species radiation by sexual selection.

\section{Methods \\ Field Collections, Electric Signal Recordings, and Species Designations}

We made extensive collections of mormyrids from Balé Creek and Loa Loa Rapids (fig. 2) during a 3-week period 
in July 2006. Taxonomic sampling for all measurements and analyses was based on the species lists generated from these 2006 collections (table B1). To investigate variation in morphology and electric signals, we also relied on additional specimens collected from 1993 to 2002. Table B1 provides sample sizes for all trait complexes.

Elsewhere (Sullivan et al. 2000, 2002, 2004; Arnegard et al. 2005, 2006), we provide detailed methods for collecting mormyrids and recording their EODs, which we did at the Institut de Recherches en Écologie Tropicale (IRET) field station, near Makokou, Gabon. Briefly, we made A/D recordings of individuals in water taken from the site of collection (conductivity $=12-30 \mu \mathrm{S} / \mathrm{cm}$; temperature $=$ $22^{\circ}-26^{\circ} \mathrm{C}$ ). The standard geometry of chloridized silver wire electrodes was used, and EODs were amplified (bandwidth: DC-50 kHz or $0.0001-50 \mathrm{kHz})$ and digitally captured at $96-1,000 \mathrm{kHz}$ (16-bit A/D converter; IOtech). No temperature correction of EODs was necessary because of the narrow range of water temperatures during recording (Arnegard et al. 2005; Lavoué et al. 2008b). After making the recordings, we euthanized each fish with an overdose of the anesthetic MS222 (tricaine methanesulfonate), tagged it with a permanent specimen number, and fixed it in $10 \%$ formalin (phosphate buffered) as the specimen lay flat in a tray of the fixative for 2 weeks. We then transferred all specimens to $70 \%$ ethanol for long-term storage and deposited them in the Cornell University $\mathrm{Mu}$ seum of Vertebrates (CUMV; Ithaca, NY).

The nominal mormyrid species investigated here were recognized as distinct species before this project. Some of the Paramormyrops species are still awaiting formal taxonomic description, so we refer to them by their established cheironyms (e.g., Paramormyrops sp. SZA). Nevertheless, these nominal Paramormyrops species, as well as the other mormyrid species in this article, are known to be valid biological species based on integration of morphological, EOD, and genetic data (e.g., Sullivan et al. 2000, 2002, 2004; Arnegard and Hopkins 2003; Lavoué et al. 2004, 2008a; Sullivan and Hopkins 2004; Arnegard et al. 2005; Hopkins et al. 2007). None of the nominal species we investigate is defined simply on the basis of unique electric signals. By contrast, species status remains uncertain for the type 1 and type 2 morphs of the "magnostipes" complex, known to differ in EODs and male body size distributions but not microsatellite genotypes (Arnegard et al. 2005, 2006). These Paramormyrops morphs were included in our main analyses, but we also evaluated the sensitivity of the overall results to excluding them (see "Sensitivity Analysis").

\section{Wavelet Analysis of Electrical Courtship Signals}

Our analysis used only dry-season recordings of mormyrid EODs. During the mormyrid breeding season in Gabon, when rainfall is the heaviest (Arnegard et al. 2006), adult males of many mormyrid species exhibit longer-duration EODs that are themselves species specific (Hopkins and Bass 1981; Moller 1995; Hopkins 1999; see discussion in Lavoue et al. 2008b). Because of the difficulty of working in Gabon at this time of year (e.g., it can be difficult to collect mormyrids in rivers swollen from the rains), insufficient samples of exaggerated male EODs have been collected for several species (app. A). In Paramormyrops, the few EOD waveforms that have been recorded from males at the time of breeding seem to be even more divergent than female EODs, apparently lying at the fringes of signal space (see fig. 5 in Arnegard and Hopkins 2003). Given this lack of male recordings, we restrict our analysis of electric signal variation to the species-typical femalelike EODs exhibited by both breeding females and adult males outside the breeding season. In addition to the female preferences for male EODs seen in laboratory studies (Machnik and Kramer 2008; Feulner et al. 2009a), electrical playbacks to breeding males (Paramormyrops spp.) at the IRET field station suggest that male mate choice targets variable features of these femalelike EODs (Hopkins and Bass 1981; Arnegard et al. 2006).

Following the approach of Crampton et al. (2008), we used discrete wavelet analysis to quantify EOD variation. This time-frequency-based digital signal-processing procedure has several advantages over other available methods for measuring biologically relevant signal variation among mormyrids (app. B in the online edition of the American Naturalist). Figure 3 shows raw traces of the 284 EODs (one EOD per individual) that we analyzed in this manner. Using MATLAB, version 7.0 (MathWorks, Natick, MA), we filtered EOD recordings with a Butterworth digital filter (60-kHz cutoff), resampled them to $100 \mathrm{kHz}$, energy normalized them, and aligned them in time by center of energy (as defined in app. B). We ensured that the total number of samples for each of these conditioned EODs was 1,024 . We then subjected the conditioned waveforms to the discrete wavelet transform (DWT), using the Symmlet-4 wavelet base, generating 1,024 DWT coefficients, including one scaling coefficient (Mallat 1999). Appendix B provides a more detailed description of these methods.

All 1,024 DWT coefficients made up the raw character matrix describing electric signal variation, which was used for the main analysis of our study. However, in a sensitivity analysis, we examined the robustness of our findings to a major variation in the method of digital signal processing. Landmark-based methods for EOD analysis have centered all waveforms under consideration on a specific EOD landmark (e.g., Arnegard and Hopkins 2003; Arnegard et al. 2005). Thus, we also varied our method such that all EODs were centered at the first major head-positive peak, P1 


\section{Paramormyrops species flock}

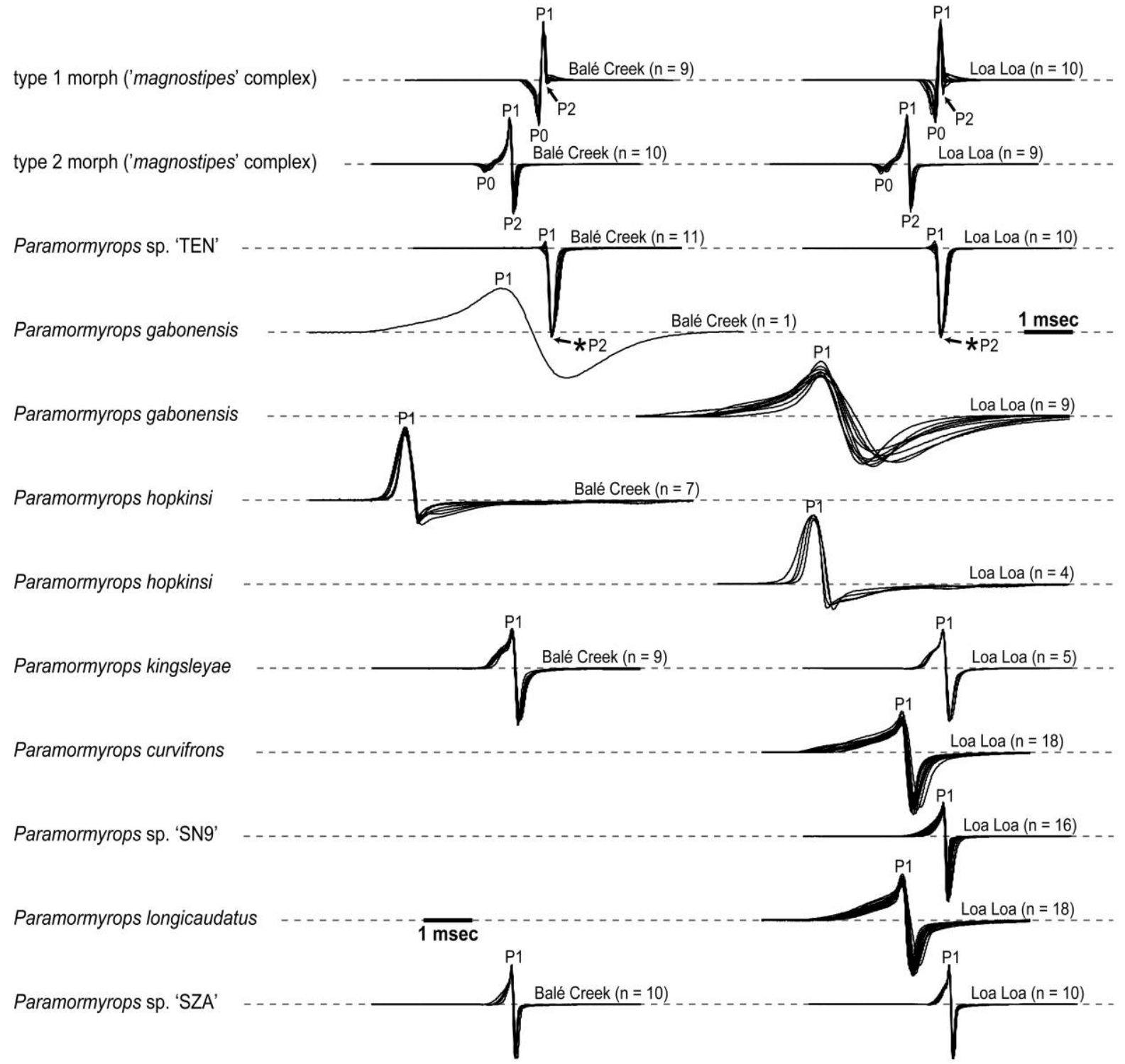

Figure 3: Electric organ discharges (EODs) of all individuals used for measuring electric signal variation at Balé Creek (left) and Loa Loa Rapids (right). Amplitude-normalized EODs are grouped by taxon and site and plotted head-positive-up on the same timescale $(\mathrm{bars}=1 \mathrm{~ms})$. When the peak P1 is always the largest positive peak in the waveforms of each group, EODs are aligned in time at this waveform landmark for the purpose of plotting them here. In the cases of Paramormyrops sp. TEN and Stomatorhinus ivindoensis, P1 is not necessarily the largest head-positive peak in the waveform, requiring manual P1 alignment. In these exceptional cases EODs are aligned here at P2 (asterisks), although manual P1 alignment was nevertheless used for centering EODs before the discrete wavelet transform performed for the sensitivity analysis.

(shown in fig. 3). The Symmlet-4 wavelet base was again used for DWT. This simple change in EOD centering resulted in a drastically altered set of 1,024 DWT coefficients, which were used to describe waveform variation for the sensitivity analysis. This large change in output structure, in turn, provided a good test of the robustness of our results to variation in the resulting matrices of DWT coefficients.

\section{Quantification of Trophic Ecology}

As a quantitative measure of trophic ecology, we analyzed nitrogen $(\mathrm{N})$ and carbon $(\mathrm{C})$ stable isotope ratios of the 


\section{Other mormyrid groups}

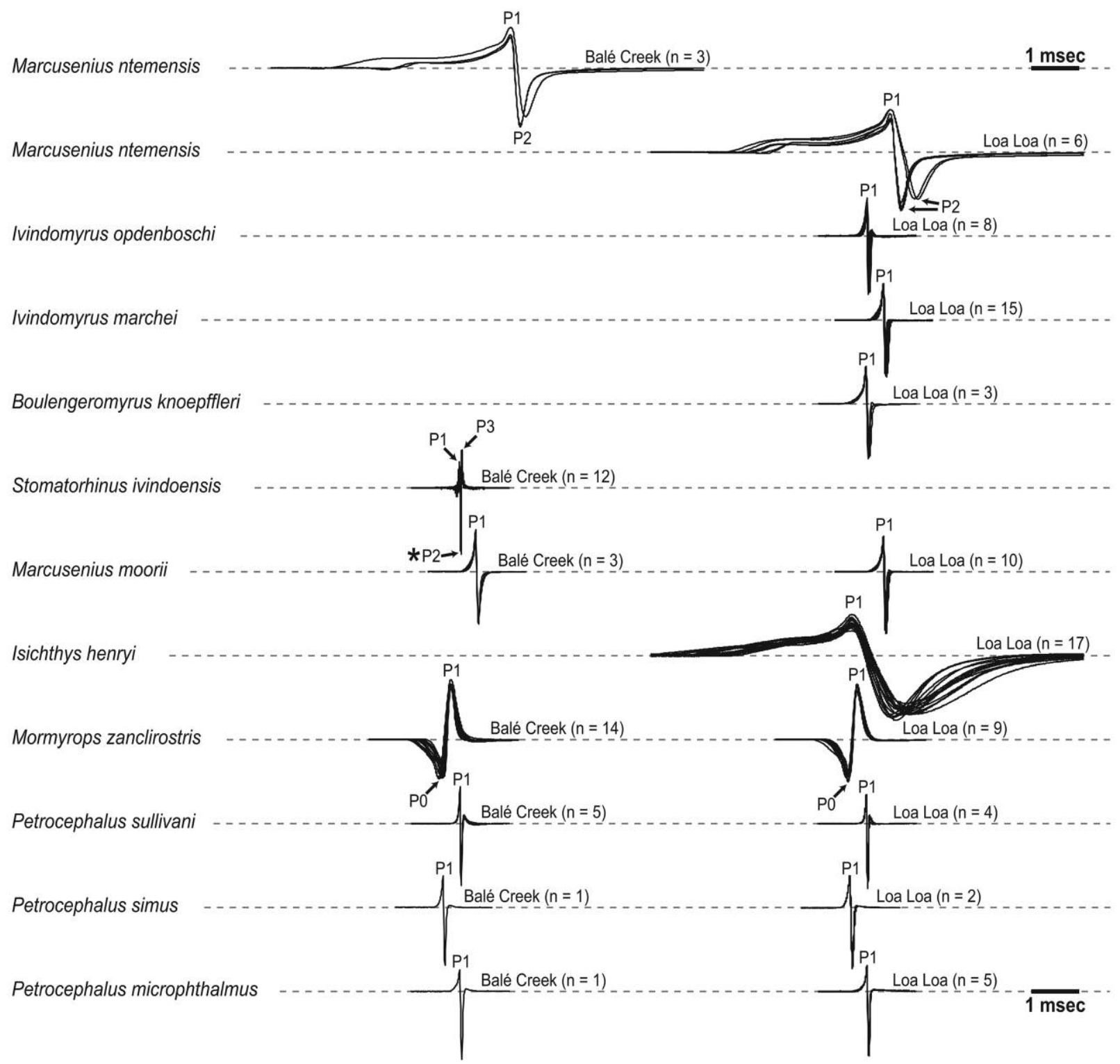

Figure 3 (Continued)

mormyrids collected in 2006. Stable isotopes of C and N in animal tissues reflect dietary patterns over periods of weeks to years (McIntyre and Flecker 2006). Carbon isotope ratios indicate the derivation of energy used by an animal because differences arising from plant metabolic pathways (e.g., C3 vs. C4) and aquatic habitats (e.g., planktonic vs. benthic) are largely conserved during trophic transfers (Fry 2006). Nitrogen isotope ratios indicate trophic position within the food web due to differential retention of the heavier isotope in consumer tissues (Post 2002). Together, $\mathrm{C}$ and $\mathrm{N}$ isotope ratios create a bivariate trophic space in which each species can be placed on the basis of analysis of replicate individuals. Interpretation of stable isotope data is complex because taxonomically distinct prey may yield similar isotope ratios in their consumers or because closely related prey may differ substantially in the isotope ratio that they pass to consumers. While acknowledging such complexities (e.g., Hoeinghaus 

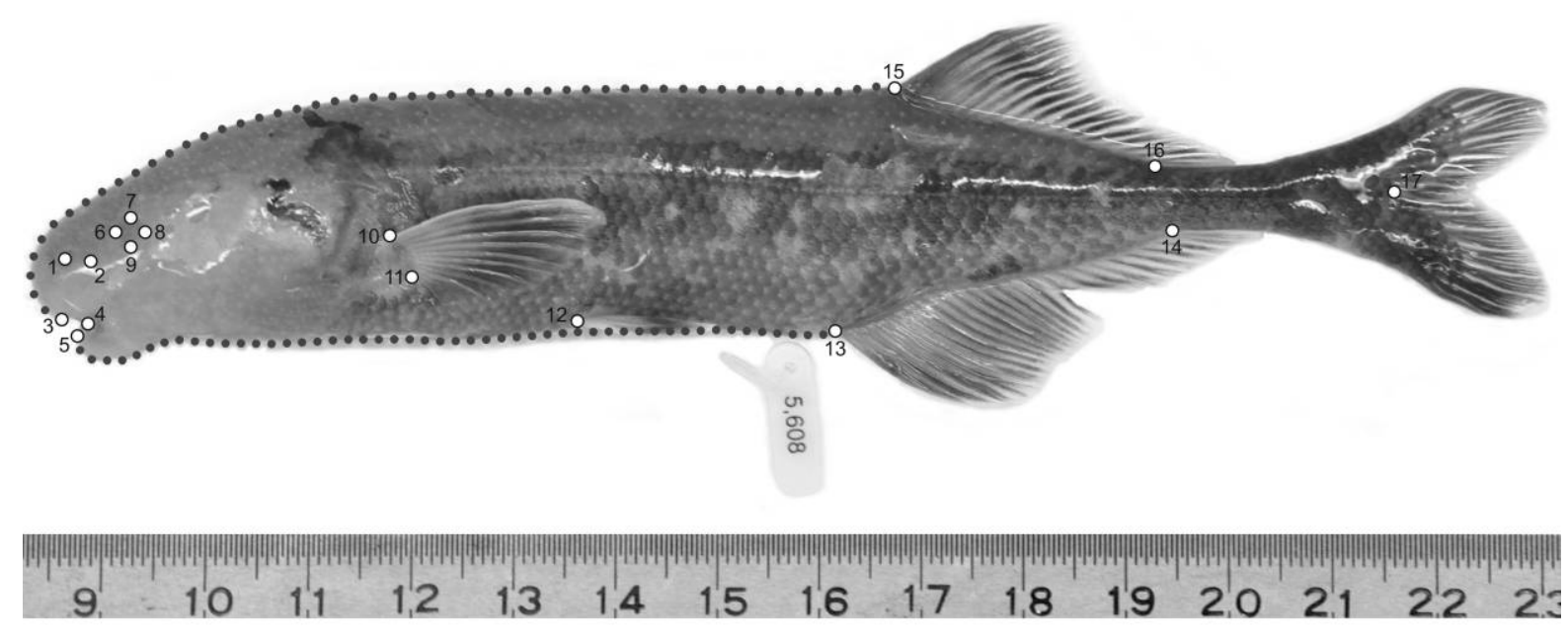

\section{Landmarks}

1: inflow naris

2: outflow naris

3: anterior tip of the upper jaw

4: corner of the mouth

5: anterior tip of the lower jaw

6: anterior margin of the orbit

7: dorsal margin of the orbit

8: posterior margin of the orbit
9: ventral margin of the orbit

10: dorsal insertion of the pectoral fin

11: ventral insertion of the pectoral fin

12: anterior insertion of the pelvic fin

13: anterior insertion of the anal fin

14: posterior insertion of the anal fin

15: anterior insertion of the dorsal fin

16: posterior insertion of the dorsal fin

17: posterior midpoint of the caudal peduncle

Figure 4: Morphological landmarks (circles with numbers) and semilandmarks (small points without numbers) capturing shape and size variation among mormyrid species and morphs. Here, Paramormyrops sp. SN9 (specimen 5608) illustrates one of the photographs of fixed specimens used to determine $x$ - and $y$-coordinates of landmarks and semilandmarks. Landmarks 1-17 are defined in the key. In addition to these morphological loci, the dorsal edge of each individual's head and anterior body was represented by 50 evenly spaced semilandmarks between landmarks 3 and 15 . The ventral edge was similarly represented by 50 semilandmarks between landmarks 5 and 13. Ruler units in centimeters.

and Zeug 2008), we used stable isotopes of $\mathrm{C}$ and $\mathrm{N}$ to assess overall differences in energy sources and trophic position among mormyrid species in this study. Stable isotope data are widely interpreted in this manner.

We dissected a sample of dorsal white muscle from each fish, excluding all scales, skin, and bones. Samples were oven-dried $\left(60^{\circ} \mathrm{C}, 48 \mathrm{~h}\right)$ at the IRET field station and stored in individual glass vials. Stable isotopes of $\mathrm{C}$ and $\mathrm{N}$ were analyzed from homogenized subsamples ( $1.2 \mathrm{mg}$ ) using a Finnigan DELTAplus mass spectrometer in the Cornell University Stable Isotope Laboratory. Appendix B provides additional details on this analysis. Results are expressed in the standard delta notation $\left(\delta^{13} \mathrm{C}, \delta^{15} \mathrm{~N}\right.$, in $\%$, relative to PDB carbonate and atmospheric $\mathrm{N}_{2}$, respectively). Figure $\mathrm{B} 1$ in the online edition of the American Naturalist shows biplots of the resulting $\delta^{13} \mathrm{C}$ and $\delta^{15} \mathrm{~N}$ values for all mormyrid individuals included in this study, together with those for select nonmormyrid fishes from each site.

\section{Geometric Morphometrics}

We made digital photographs of preserved adult and large subadult mormyrid specimens (housed at the CUMV) and used these to analyze morphometric differences (e.g., fig. 4). In the photographs, we recorded coordinates of 17 morphological landmarks similar to those used by Feulner et al. (2007) for measuring ecologically relevant shape variation in another mormyrid species radiation (Campylomormyrus of the lower Congo). We also recorded coordinates of 50 evenly spaced semilandmarks along the dorsal silhouette and 50 evenly spaced semilandmarks along the ventral silhouette to capture additional information about shape variation (fig. 4). Landmarks were superimposed using generalized Procrustes analysis (Rohlf and Slice 1990), and semilandmarks were superimposed using the minimum bending energy criterion (Green 1996; Bookstein 1997). Effects of preservation artifact (i.e., specimen bending) and the slight variation within species due 
to ontogenetic and static allometry were removed statistically (see app. B for details), producing an estimate of the unbent mean adult shape at each species' mean adult body size. This procedure produced a 130-dimensional description of body shape.

Body size was quantified as centroid size, the square root of the sum of squared distances of all landmarks from the center of the form (Bookstein 1986). This measure of body size is mathematically orthogonal to shape. Quantification of body size was based strictly on adult specimens in order to isolate evolved differences in size at maturation and maximum size from the influence of ecological patterns in population size structure. Thus, our comparisons of body size were based on the subset of specimens used in body shape analysis (table B1) that exceeded the size at which an indentation along the base of the anal fin in males indicates reproductive maturity (Herfeld and Moller 1998; Pezzanite and Moller 1998; Arnegard et al. 2006; see fig. 4).

\section{Phylogeny}

Mormyrids have been extensively studied phylogenetically (Alves-Gomes and Hopkins 1997; Lavoué et al. 2000, 2003, 2008a, 2008b; Sullivan et al. 2000, 2002, 2004). Here, our purpose was to use the existing phylogenetic framework to test relative rates of trait divergence rather than to reanalyze mormyrid phylogenetic relationships. We employed a tree topology for these taxa from a simple consensus of the best trees derived in four molecular phylogenetic studies that examined relationships at different hierarchical levels within the Mormyridae, using a number of mitochondrial and nuclear markers (Lavoué et al. 2000, 2003; Sullivan et al. 2000, 2004). To estimate branch lengths on this fixed topology, we used cytochrome $b$ (cyt $b$ ) sequences because these were available for all but one species (Paramormyrops sp. SN9). This undescribed species had not been sampled in any previous phylogenetic study of mormyrids. We obtained a new cyt $b$ sequence from this species and placed it into the topology, as described in appendix B. These cyt $b$ sequences were in all cases collected from individuals captured within a 3-km radius on the Ivindo River and tributary creeks, including sites at Loa Loa Rapids, Balé Creek, or neighboring Bialé Stream (fig. 2, inset). The outgroup cyt $b$ sequence was taken from the electrogenic sister taxon to the Mormyridae, Gymnarchus niloticus, which does not occur in or around Gabon. GenBank accession numbers and lengths of all sequences are provided in table $\mathrm{B} 2$ in the online edition of the American Naturalist.

We used a GTR $+\mathrm{I}+\Gamma$ model of sequence evolution (Yang 1994) to infer maximum likelihood cyt $b$ branch lengths on the consensus topology, using GARLI, version
0.951 (Zwickl 2006). The resulting tree is shown in figure $1 B$. The tree obtained by removing the constraint of the consensus topology and estimating topology as well as branch lengths from the cyt $b$ data (using the same model and software) has a topology that differs at four nodes (fig. B2). Three of these occur within the rapidly diversifying Paramormyrops clade, where we strongly suspect that the multilocus nuclear amplified fragment length polymorphism data used by Sullivan et al. (2004) are superior for accurately recovering phylogenetic relationships. To examine the sensitivity of our main analysis to uncertainties in tree topology, we conducted our trait divergence rate comparisons by using both this unconstrained tree and the preferred-topology consensus tree. Before the analyses of trait divergence rates, these two trees were converted to ultrametric trees, using the penalized-likelihood method implemented in the program r8s, version 1.70 (Sanderson 2003). Phylogenetic distances in the ultrametric tree were scaled to vary from 0 to 1 . A more detailed description of all phylogenetic methods is provided in appendix $B$ as supporting information.

\section{Analysis of Trait Divergence Rates}

We quantified and compared evolutionary divergence rates for the above traits, using R, version 2.9.2 (R Core Development Team 2009). Before doing so, we employed principal component analysis (PCA) to reduce dimensionality of the high-dimensional trait complexes (i.e., electric signals and body shape). Before dimension reduction, the raw character matrices (for the main analysis) included 1,024 DWT coefficients (signals), 130 shape coefficients (morphology), two stable isotope ratios (trophic ecology), and one centroid size (body size). In the main analysis, we reduced these data matrices to the minimum number of principal component (PC) axes needed to explain $95 \%$ of the total variation in the raw data. This resulted in six PC axes for shape and six PC axes for signals. The one trait axis for body size and two trait axes for trophic ecology required no dimension reduction. In addition to our $95 \%$ criterion, we also investigated how retaining fewer axes for signals and shape affected our findings (see "Sensitivity Analysis").

Next, we used multivariate analysis of variance (MANOVA) to evaluate differences among species/morphs in each of the reduced-dimension trait spaces. From these, we extracted only the first two canonical variate axes associated with each MANOVA (except for body size), and we plotted individuals on these two axes to visualize patterns of variation among taxa (fig. 5). In the case of body size, differences among taxa were evaluated by ANOVA on the natural logarithm of centroid size.

Comparing divergence rates among disparate traits re- 


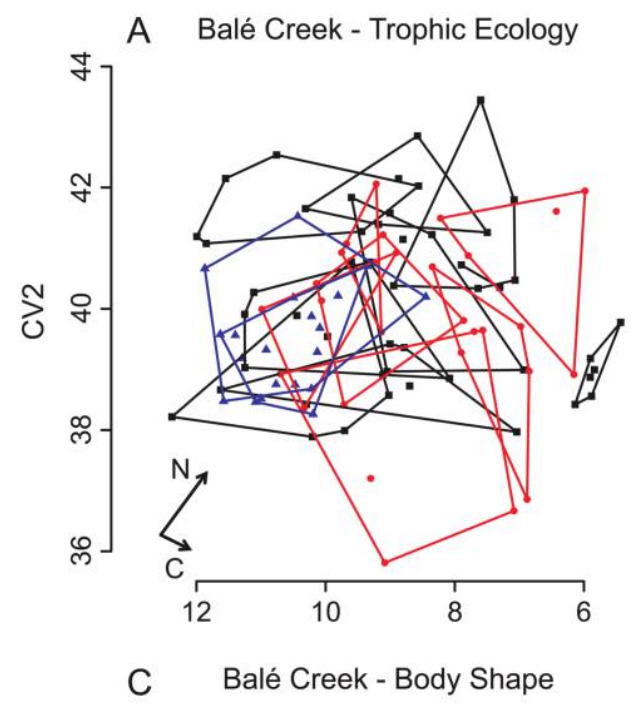

B Loa Loa - Trophic Ecology
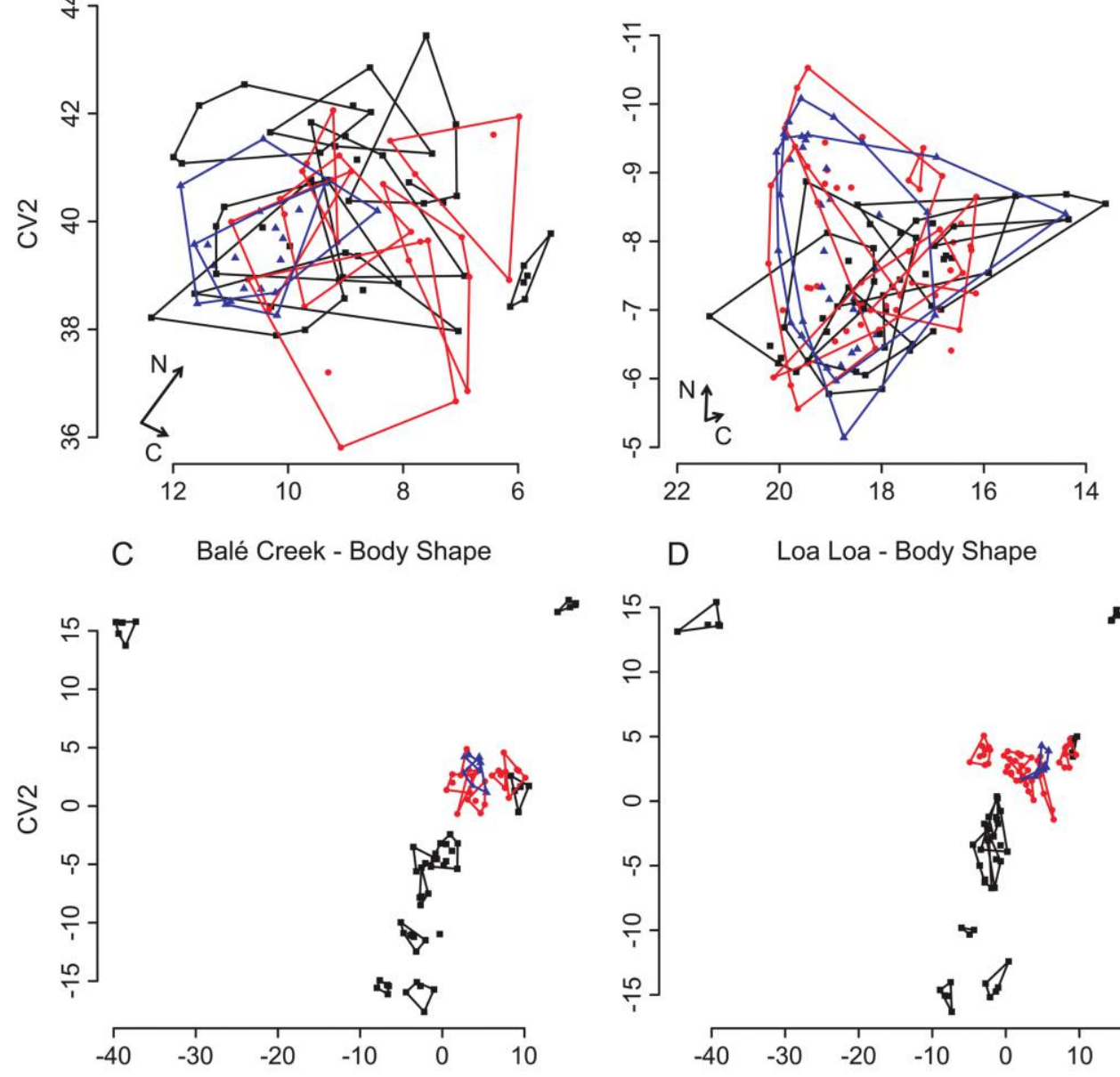

D Loa Loa - Body Shape

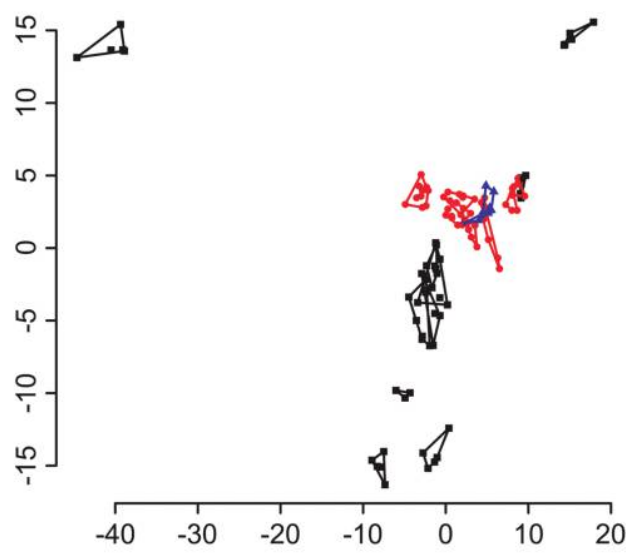

E Balé Creek - Electric Signals
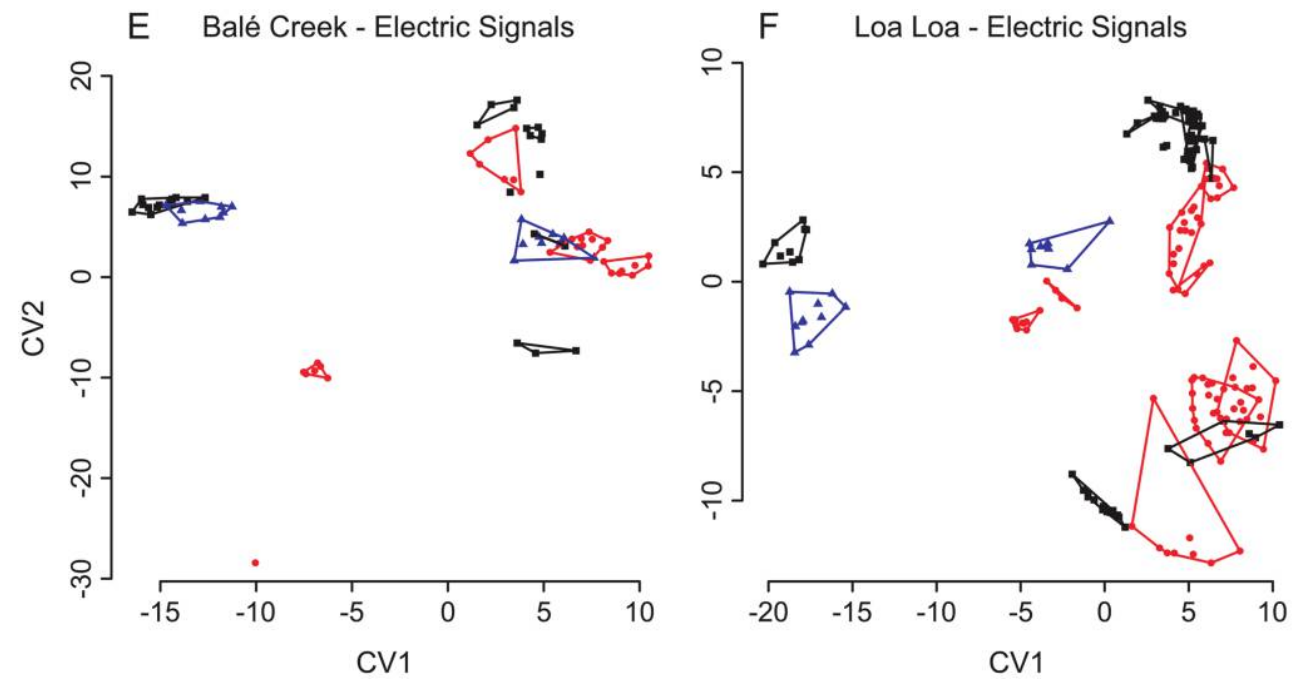

Figure 5: Trait spaces for three complex phenotypes of mormyrids in Balé Creek (left) and Loa Loa Rapids (right). Bivariate representations of traits along the first two canonical variate axes (CV1 and CV2) are shown for trophic ecology $(A, B)$, body shape $(C, D)$, and electric signals $(E, F)$. Following figure 1, individuals (points) are color-coded by hierarchical position in the mormyrid phylogeny: Paramormyrops morphs $=$ blue triangles; other Paramormyrops $=$ red circles; all other mormyrids = black squares. All individuals of each species or morph are enclosed in a polygon to aid visualization of species differences. Vectors at the bottom left of $A$ and $B$ indicate direction and magnitude of increases in $\delta^{13} \mathrm{C}$ and $\delta^{15} \mathrm{~N}$ by $1 \%$. 
quires a scale-invariant measure of phenotypic variation applicable to each trait space (Gingerich 1993; Hendry and Kinnison 1999). To achieve this, generalized rates of trait divergence have been calculated previously as haldanes, which scale univariate traits in terms of standard deviations of change per generation, or using Mahalanobis distance as an analogue of the haldane for multivariate character complexes (e.g., Lerman 1965; Cherry et al. 1982; Eldredge et al. 2005). Both approaches require continuous measures of trait variation. Most previous estimates of divergence rates have been applied to rates of morphological evolution in fossil lineages, for which variation in songs, color patterns, or other displays is unknown.

To calculate divergence rates for the traits considered in this study, we used Mahalanobis distances $(D)$, which scale among-group trait distances according to patterns of within-group trait variance and covariance (Mahalanobis 1936). Since sample sizes were low for some species and traits, we calculated a pooled within-species variancecovariance matrix for each trait space. We used the $\mathrm{R}$ function "mahalanobis" to compute $D^{2}$ between each pair of species. We then calculated the square root of this value to yield $D$. For any given phylogenetic distance between two species, a greater value of $D$ (hereafter referred to as "trait distance") implies a faster rate of divergence relative to within-species trait variances and covariances.

We investigated phylogenetic signal and correlations among character sets using Mantel tests rather than simpler alternatives such as independent contrasts (Felsenstein 1985 ) or the $K$ statistic (Blomberg et al. 2003). Mantel tests were necessary because of the multivariate nature of the data sets. No other current method exists to measure multivariate phylogenetic signal or to correlate Mahalanobis distances with other distances in a phylogenetic context. Thus, we investigated correlations between trait complexes, controlling for phylogenetic relationships, by means of three-way partial Mantel tests. These tests were performed on pairs of trait distance matrices, as well as the matrix of phylogenetic distances. For each comparison, we calculated the Mantel test statistic, $z$, and evaluated its significance using 9,999 matrix permutations.

Finally, we evaluated patterns of accumulation in trait distance $(D)$ over ultrametric tree distance (i.e., relative evolutionary time). We evaluated the fit of these data to both a simple linear regression model forced through the origin and the following breakpoint regression model, also lacking an intercept term:

$$
y=\beta_{1} x+\beta_{2}(x-c) \delta
$$

Here, $y$ is trait distance; $x$ is phylogenetic distance (as defined above); $\beta_{1}$ is the slope term of the line segment before the breakpoint in the regression; $\beta_{2}$ is a second slope term added to $\beta_{1}$ in the line segment after the breakpoint; $c$ is the breakpoint abscissa value; and the indicator variable, $\delta$, equals 1 when $x>c$ and 0 otherwise. We fitted this breakpoint regression model using least squares, and we compared it to the simple linear no-intercept model, using a general linear test (Neter and Wasserman 1974). Trait distances were often found to increase initially with relative evolutionary time but then to level off at some point. Therefore, for quantifying and comparing trait divergence we preferred the breakpoint regression models, which always fitted the data much better than simple linear regression. The first slope coefficient in the breakpoint regression models, $\beta_{1}$, reflects the rates of trait divergence during the earliest stages of species radiation. We compared breakpoint regression models between each pair of trait data sets (e.g., signals vs. body size) using a general linear test procedure (these and all other tests two sided). We compared a model where the two trait data sets had shared slope and breakpoint parameters to a model where these parameters differed between the two data sets.

\section{Sensitivity Analysis}

Estimated trait divergence rates $\left(\beta_{1}\right.$ in the breakpoint regression models) could potentially depend strongly on the following features of our methodology: (i) inclusion of the type 1 and type 2 morphs of the magnostipes complex, very young Paramormyrops taxa for which species status is still uncertain; (ii) method of EOD centering before discrete wavelet analysis; (iii) tree topology; and (iv) threshold for dimension reduction before the quantification and comparison of divergence rates. To explore the robustness of our findings, we repeated our analysis of trait divergence rates several times, employing a perturbation to each of these methodological features while keeping all others as originally described. First, we evaluated the effects of excluding both morphs of the magnostipes complex from the analysis. Second, we used P1 centering to align EODs in time before wavelet analysis. Third, we investigated how the findings were affected when we used a tree topology produced by maximum likelihood analysis of the cyt $b$ sequences on which we imposed no topological constraints based on the consensus of published results for other genetic markers. Fourth, we evaluated the consequences of retaining fewer measurement dimensions characterizing shape and signal variation. In one such perturbation, we reduced trait spaces for signals and body shape to two dimensions using PCA. In another perturbation, we reduced our signal, shape, and isotope data to one dimension each. In both cases, only one size axis (centroid size) was available for comparison.

Further, to ensure that any rate differences between trait complexes found using breakpoint regression were not 
simply the result of differences in breakpoints, we also compared slopes of simple linear regression models fitted to the data for only recently diverged species. Our threshold for including species in these comparisons was a scaled ultrametric tree distance of less than 0.15 (i.e., half of maximum divergence in the Paramormyrops species flock). This is analogous to using the breakpoint regression models to compare initial rates of divergence $\left(\beta_{1}\right)$ between trait complexes with all breakpoints fixed at the halfway point of the Paramormyrops radiation.

\section{Results}

Mormyrid taxa that are extremely closely related are as divergent in electric signals as are lineages that split long ago (fig. 3). In contrast, the magnitude of ecological divergence depends on the level of phylogenetic relatedness among species, such that more distantly related pairs of species are more ecologically distant. At the broadest phylogenetic scale, which includes all mormyrid lineages (fig. 1 ), electric signals (EODs), trophic ecology, and body shape differ among species (MANOVA, $P<.0001$; fig. 5, all colors), as does body size (ANOVA, $P<.0001$; fig. 6; table 1). All traits also vary significantly among species within just the Paramormyrops radiation (table 1), but there is much greater overlap in ecological traits than in electric signals at this scale of comparison (fig. 5, red, blue; fig. 6). When we compare only the two most closely related taxa, the type 1 and type 2 morphs of Paramormyrops

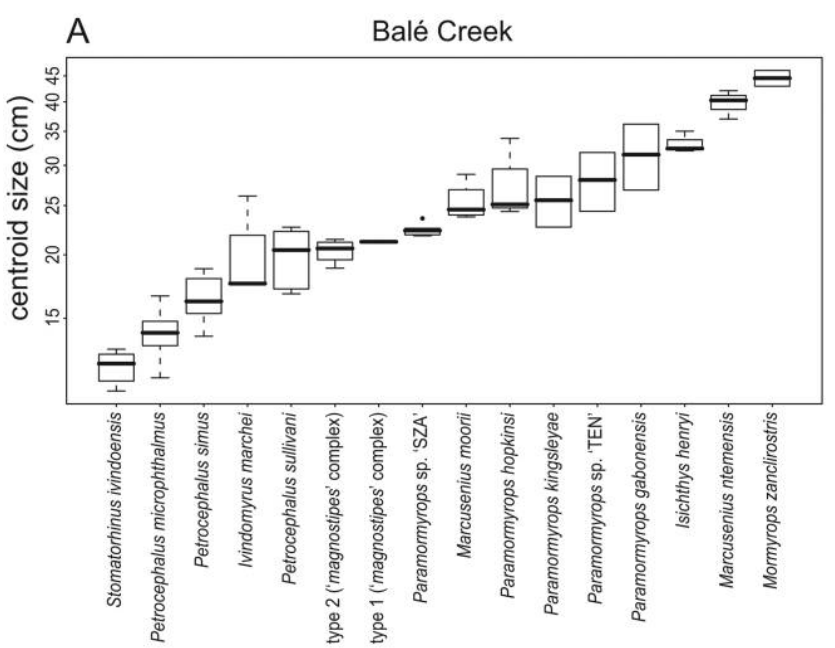

(magnostipes complex), we find that signals differ widely even at this earliest stage of divergence (MANOVA, $P<$ .0001 ; fig. 5, blue triangles). By contrast, these young morphs appear indistinguishable in trophic ecology and body shape (fig. 5 ; table 1), although they have been shown previously to differ in body size of breeding males but not females (Arnegard et al. 2006). Accounting for phylogeny, we find no evidence of correlated evolution between signals and ecological traits within Paramormyrops or among all mormyrid species (table 2).

Describing changes in trait distances (Mahalanobis distances) over evolutionary time (branch lengths on the ultrametric tree) revealed that the tempo of signal divergence in mormyrids has far exceeded rates of divergence in ecological traits. For both body size and trophic ecology, typical trait distances between species were relatively low across the entire phylogeny (fig. 7). Differences in body shape increased substantially with phylogenetic distance, but major differences among species in signal space were evident in all comparisons regardless of branch length.

Breakpoint regressions, which fitted the data much better than simple linear models, indicated that trait distances almost always leveled off or even decreased slightly after an initial period of divergence (fig. 7; table 3). Comparing models in which the two traits had shared slope and breakpoint parameters to models in which these parameters differed between traits showed that divergence rates were always faster for electric signals than for ecological traits in Paramormyrops, as well as across all mormyrids studied

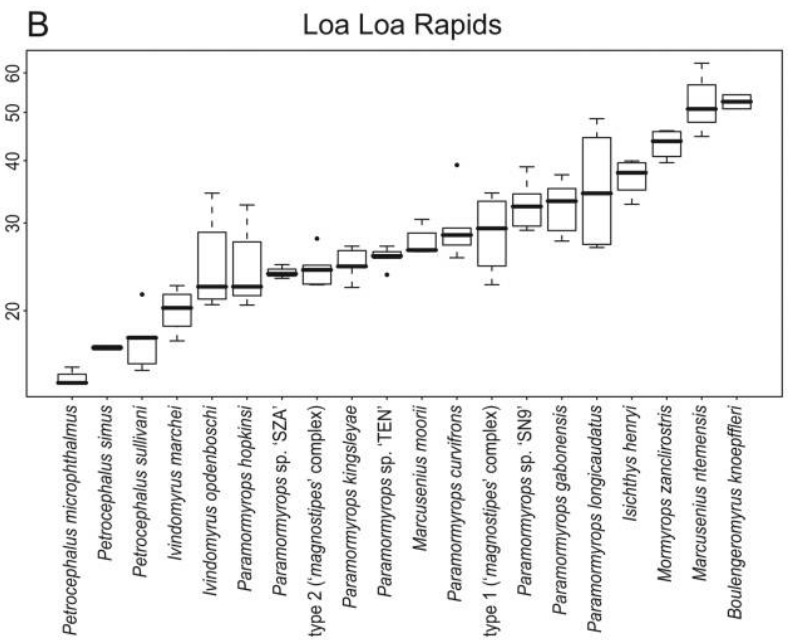

Figure 6: Variation in adult body size among mormyrid species at Balé Creek $(A)$ and Loa Loa Rapids (B). Centroid size of each individual, a measure of body size, is the square root of the sum of squared distances between each morphological landmark (shown in fig. 4) and the center of the form. Boxplots on a natural-log scale show medians (thick horizontal segments), interquartile ranges (IQRs) around the medians (boxes), nonoutlier ranges (whiskers), and outliers (points). Any observation more than $1.5 \times$ IQR lower than the first quartile or $1.5 \times$ IQR higher than the third quartile is considered an outlier. 
Table 1: Statistical analysis of trait variation among mormyrid species and morphs in each community

\begin{tabular}{|c|c|c|c|c|c|c|c|}
\hline \multirow[b]{2}{*}{ Taxa, site, and trait complex } & \multicolumn{3}{|c|}{ ANOVA } & \multicolumn{4}{|c|}{ MANOVA } \\
\hline & $F$ & $\mathrm{df}$ & $P$ & $F$ & $\mathrm{df}$ & $P$ & $\overline{\text { Wilks's } \lambda}$ \\
\hline \multicolumn{8}{|l|}{ All mormyrids: ${ }^{a}$} \\
\hline \multicolumn{8}{|l|}{ Balé Creek: } \\
\hline Trophic ecology & & & & 8.502 & 36,158 & $<.0001$ & .1159 \\
\hline Body size ${ }^{\mathrm{b}}$ & 40.74 & 15,46 & $<.0001$ & & & & \\
\hline Body shape & & & & 88.08 & $102,366.2$ & $<.0001$ & $<.0001$ \\
\hline Electric signals & & & & 100.1 & $78,353.5$ & $<.0001$ & $<.0001$ \\
\hline \multicolumn{8}{|l|}{ Loa Loa: } \\
\hline Trophic ecology & & & & 5.657 & 36,244 & $<.0001$ & .2971 \\
\hline Body size ${ }^{\mathrm{b}}$ & 22.81 & 19,69 & $<.0001$ & & & & \\
\hline Body shape & & & & 105.9 & $114,519.7$ & $<.0001$ & $<.0001$ \\
\hline Electric signals & & & & 96.83 & $114,945.7$ & $<.0001$ & $<.0001$ \\
\hline \multicolumn{8}{|l|}{ Paramormyrops only: ${ }^{\mathrm{a}}$} \\
\hline \multicolumn{8}{|l|}{ Balé Creek: } \\
\hline Trophic ecology & & & & 7.711 & 16,80 & $<.0001$ & .1547 \\
\hline Body size $^{\mathrm{b}}$ & 4.137 & 6,12 & .0175 & & & & \\
\hline Body shape & & & & 8.127 & $42,97.3$ & $<.0001$ & .0009 \\
\hline Electric signals & & & & 194.2 & $36,174.0$ & $<.0001$ & $<.0001$ \\
\hline \multicolumn{8}{|l|}{ Loa Loa: } \\
\hline Trophic ecology & & & & 5.628 & 18,162 & $<.0001$ & .3785 \\
\hline Body size ${ }^{\mathrm{b}}$ & 4.422 & 9,40 & .0005 & & & & \\
\hline Body shape & & & & 23.61 & $54,254.4$ & $<.0001$ & .0001 \\
\hline Electric signals & & & & 88.75 & $54,483.9$ & $<.0001$ & $<.0001$ \\
\hline \multicolumn{8}{|l|}{ Morphs only: } \\
\hline \multicolumn{8}{|l|}{ Balé Creek: } \\
\hline Trophic ecology & & & & .4886 & 2,17 & .6219 & .9456 \\
\hline Body size & .4512 & 1,3 & .5499 & & & & \\
\hline Body shape & & & & 2.798 & 6,1 & .4281 & .0562 \\
\hline Electric signals & & & & 190.1 & 6,11 & $<.0001$ & .0100 \\
\hline \multicolumn{8}{|l|}{ Loa Loa: } \\
\hline Trophic ecology & & & & .0198 & 2,37 & .9804 & 9989 \\
\hline Body size $^{\mathrm{b}}$ & 3.560 & 1,8 & .0959 & & & & \\
\hline Body shape & & & & 4.440 & 6,4 & .0853 & .1306 \\
\hline Electric signals & & & & 314.6 & 6,12 & $<.0001$ & .0060 \\
\hline
\end{tabular}

${ }^{a}$ Including both morphs of the magnostipes complex.

${ }^{\mathrm{b}}$ Body size $=\ln ($ centroid size).

(all $P<.02)$. Paramormyrops species/morphs have diverged three to four times faster in signal space than in ecomorphological shape space. The rate disparity between signals and body size or trophic ecology was ninefold to 17-fold in Paramormyrops, and relative rates of signal evolution appeared even more explosive when all mormyrids were considered (table 4).

Sensitivity analysis demonstrated that the evidence for more rapid divergence of electric signals than of ecological traits was robust to all of the following methodological permutations to our breakpoint regressions: (i) exclusion of the type 1 and type 2 morphs of Paramormyrops, (ii) EOD centering at P1 before discrete wavelet analysis of signals, (iii) use of an unconstrained phylogenetic topology derived from cyt $b$, and (iv) greater amounts of dimension reduction applied to the high-dimensional trait spaces be- fore quantifying divergence rates. Under each of these scenarios, the analysis still indicated that electric signals have diverged significantly faster than trophic ecology, body shape, and body size during radiation of the Paramormyrops species flock. All results of the sensitivity analysis are summarized in table 5 . We also confirmed that the significant rate differences we estimated on the basis of $\beta_{1}$ from the breakpoint regression models were not merely due to variation in the position of the breakpoint. Here, again, we found that electric signals always exhibited a significantly faster increase in trait distance with increasing phylogenetic distance when only recently diverged species were considered, no breakpoint was allowed, and regressions were still forced through the origin (in the online edition of the American Naturalist, see fig. C1 and table C1). 
Table 2: Mantel tests for correlations between electric signals and ecological traits, controlling for phylogenetic relationships among species

\begin{tabular}{lcc}
\hline Community, taxa, and traits & $R$ & $P$ \\
\hline Balé Creek: & & \\
Paramormyrops: & & \\
$\quad$ Signals and trophic ecology & -.331 & .9538 \\
$\quad$ Signals and body shape & +.083 & .4017 \\
$\quad$ Signals and body size & +.349 & .0883 \\
All mormyrids: & & \\
$\quad$ Signals and trophic ecology & -.103 & .7118 \\
$\quad$ Signals and body shape & +.054 & .1931 \\
$\quad$ Signals and body size & +.170 & .1970 \\
Loa Loa: & & \\
Paramormyrops: & & \\
$\quad$ Signals and trophic ecology & -.222 & .8932 \\
$\quad$ Signals and body shape & -.212 & .7721 \\
$\quad$ Signals and body size & -.133 & .7738 \\
All mormyrids: & & \\
$\quad$ Signals and trophic ecology & -.103 & .7938 \\
$\quad$ Signals and body shape & +.251 & .1004 \\
$\quad$ Signals and body size & +.009 & .3740 \\
\hline
\end{tabular}

\section{Discussion}

Our quantitative analyses demonstrate rapid rates of electric signal divergence in the apparent absence of environmental constraints or correlated ecological divergence. Sexual signals have evolved much faster than all measured ecological traits in the Paramormyrops radiation and in mormyrids in general. This pattern of trait evolution suggests that sexual selection on signals has been a more important early driver of species radiation in these fishes than has natural selection on ecological traits or ecologically based reinforcement of signal differences.

Rapid signal evolution has been observed between ecologically similar but geographically isolated populations in many other animal radiations (Rundell and Price 2009). At least some spatial isolation has also likely played an important role in facilitating the initial stages of Paramormyrops diversification by divergent sexual selection (Arnegard and Kondrashov 2004; Coyne and Orr 2004; Kirkpatrick and Nuismer 2004). Though we infer that sexual selection has had primacy in mormyrid speciation, ecological divergence has probably also played a supplementary role. Coexistence is often thought to be unstable between ecologically similar allopatric species sharing the same niche (Schoener 1989) but differing in courtship signals, although the time to competitive exclusion under neutral ecological dynamics can be quite long (Hubbell 2001). In addition to dramatic signal differences, we also demonstrate smaller yet significant differences in all measured ecological traits (body size, body shape, and trophic ecology) among closely related Paramormyrops species (ta- ble 1). Such differences may help to explain the coexistence of so many mormyrid species within the diverse electric fish communities of the Ivindo River. These differences are also consistent with natural selection on ecological traits contributing to the further divergence of signals and species after secondary sympatry is established (Gerhardt 1999; Servedio and Noor 2003). Members of our research team have been sampling mormyrids in Balé Creek and Loa Loa Rapids for more than 30 years (1975-present), and the composition of the mormyrid assemblage at each site has remained qualitatively similar over this time period. This suggests that assemblage structure is stabilized by ecological niche partitioning, though we cannot fully exclude the possibility of ecological neutrality of some species.

Most previous attempts to use comparative phylogenetic methods to test the importance of sexual selection during species radiation have compared diversification rates between clades differing in the propensity for sexual selection (Barraclough et al. 1995; Price 1998; Arnqvist et al. 2000; Ritchie 2007; Kazancıoğlu et al. 2009). However, the clades that have been compared differ in many respects beyond the identified targets and strengths of sexual selection. The approach we take controls for these sorts of differences by focusing on trait evolution within a single radiation. In that context, quantitative comparisons of evolutionary rates among traits that are subject to natural selection versus sexual selection offer great inferential power. Our approach can also elucidate changes in the targets of selection across the entire time course of a species radiation. In mormyrids, it appears that an initial burst of electric signal evolution by sexual selection is a fundamental part of the mechanism fueling speciation but that ecomorphological divergence eventually catches up to and even surpasses signal differences (fig. 7).

Though our study implicates sexual selection on electric signal pulses as playing a more fundamental role in the process of mormyrid species radiation than does natural selection on ecological traits, some potentially important limitations on this inference must be recognized. First, we may have failed to measure the most important ecological character complex in Paramormyrops. For instance, a single cryptic ecological trait in this group-perhaps microhabitat use or a related behavior-could be involved in species differentiation under natural selection. In a classic study of warblers (MacArthur 1958), rapidly evolving ecological differences would have been overlooked had morphology served as the proxy for ecological divergence instead of fine-scale habitat preference. Our extensive field experience studying Paramormyrops offers little evidence of such cryptic ecological traits, but we cannot exclude the possibility. Second, despite prior work on the ecological relevance of body shape variation in mormyrids (Marrero 

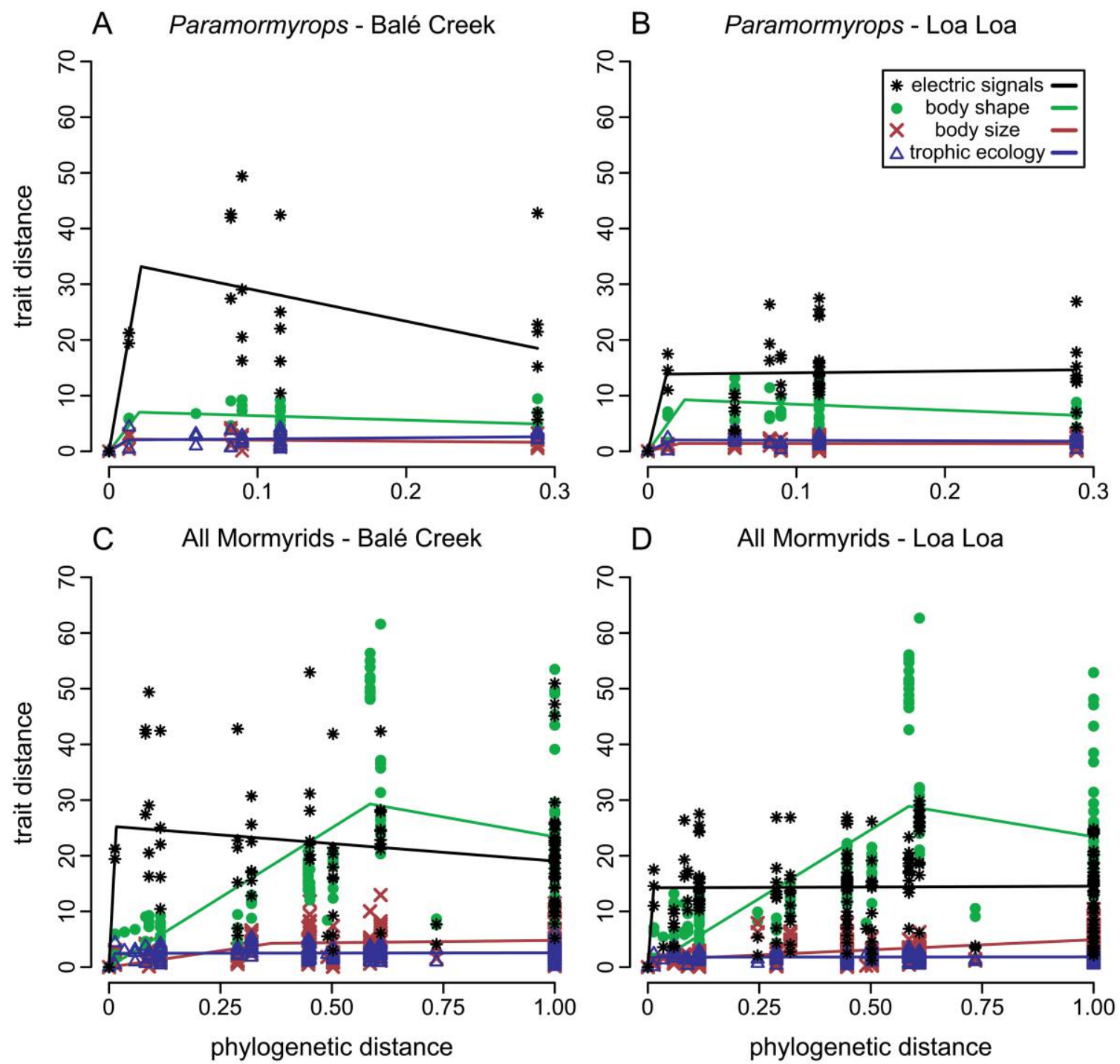

Figure 7: Rates of trait divergence measured in two mormyrid communities. Trait distance between taxa is represented for each of four character complexes (see key) as Mahalanobis distance. Ultrametric tree distance serves as a measure of phylogenetic distance (i.e., relative evolutionary time). Data are shown for the Paramormyrops species flock $(A, B)$ and all mormyrids including Paramormyrops $(C, D)$ in Balé Creek (left) and Loa Loa Rapids (right). Color-coded lines shown in each plot were estimated using breakpoint regression. In each case, the slope of the initial prebreakpoint segment describes the initial divergence rate during species radiation (reported in table 4).

and Winemiller 1993; Winemiller and Adite 1997) and stable isotope differences in fish communities (McClure et al. 2006; Helland et al. 2008), much more work is needed to fully understand the adaptive significance of ecological traits in Paramormyrops (e.g., body size; Schluter 2000). Third, we cannot be certain that our methods for measuring ecological traits were as sensitive as the digital signal-processing procedures applied to signal variation, though we selected state-of-the-art methods for quantifying all trait axes. For example, stable isotopic signatures can diverge rapidly in fish and are considered to be very sensitive measures of feeding ecology (Genner et al. 1999; Seehausen 2009; Matthews et al. 2010).

The hypothetical framework underlying the interpretation of relative rates of trait divergence that we outline in "Introduction" assumes no general differences in the responsiveness of signals and ecological traits to selection. Compared to strong divergent natural selection on a single ecological trait, weaker multifarious selection acting on several ecological traits simultaneously could be more ef- 
Table 3: Fit of a no-intercept breakpoint regression model to the relationships between trait distance and phylogenetic distance, relative to a no-intercept simple linear regression model

\begin{tabular}{|c|c|c|c|c|c|c|}
\hline Taxa, site, and trait complex & $F$ & $\mathrm{df}$ & $P$ & $\beta_{1}$ & $\beta_{2}$ & $c$ \\
\hline \multicolumn{7}{|l|}{ Paramormyrops only: ${ }^{\mathrm{a}}$} \\
\hline \multicolumn{7}{|l|}{ Balé Creek: } \\
\hline Trophic ecology & 14.8 & 35,33 & $<.0001$ & +155 & -153 & .013 \\
\hline Body size $^{\mathrm{b}}$ & 11.3 & 20,18 & .0007 & +154 & -156 & .014 \\
\hline Body shape & 38.5 & 27,25 & $<.0001$ & +345 & -353 & .020 \\
\hline Electric signals & 21.3 & 20,18 & $<.0001$ & $+1,538$ & $-1,593$ & .022 \\
\hline \multicolumn{7}{|l|}{ Loa Loa: } \\
\hline Trophic ecology & 35.3 & 44,42 & $<.0001$ & +121 & -122 & .017 \\
\hline Body size ${ }^{\mathrm{b}}$ & 12.9 & 44,42 & $<.0001$ & +65 & -65 & .021 \\
\hline Body shape & 61.0 & 44,42 & $<.0001$ & +373 & -384 & .025 \\
\hline Electric signals & 34.8 & 44,42 & $<.0001$ & $+1,100$ & $-1,098$ & .013 \\
\hline \multicolumn{7}{|l|}{ All mormyrids: ${ }^{\mathrm{a}}$} \\
\hline \multicolumn{7}{|l|}{ Balé Creek: } \\
\hline Trophic ecology & 83.6 & 170,168 & $<.0001$ & +180 & -180 & .013 \\
\hline Body size ${ }^{b}$ & 12.5 & 119,117 & $<.0001$ & +12 & -11 & .364 \\
\hline Body shape & 42.9 & 152,150 & $<.0001$ & +50 & -64 & .586 \\
\hline Electric signals & 56.5 & 90,88 & $<.0001$ & $+1,538$ & $-1,544$ & .016 \\
\hline \multicolumn{7}{|l|}{ Loa Loa: } \\
\hline Trophic ecology & 105.2 & 170,168 & $<.0001$ & +121 & -121 & .015 \\
\hline Body size $e^{b}$ & 9.6 & 189,187 & .0001 & +65 & -62 & .020 \\
\hline Body shape & 56.2 & 189,187 & $<.0001$ & +49 & -63 & .586 \\
\hline Electric signals & 105.0 & 189,187 & $<.0001$ & $+1,071$ & $-1,071$ & .013 \\
\hline
\end{tabular}

Note: In each case, the $F$ statistic and $P$ value describe the improvement in fit of breakpoint regression over simple linear regression; $\beta_{1}$ is the initial rate of divergence (estimated from breakpoint regression) for each of the indicated traits, $\beta_{2}$ is a second slope term added to $\beta_{1}$ in the line segment after the breakpoint, and $c$ is the breakpoint abscissa value.

${ }^{a}$ Including both morphs of the magnostipes complex.

${ }^{\mathrm{b}}$ Body size $=\ln ($ centroid size $)$.

fective in fostering speciation in some cases (Nosil and Harmon 2009). All else being equal (e.g., levels of genetic variation and trait heritability), strong natural selection in one dimension is expected to result in large interspecific distances in a single ecological trait, whereas weaker multifarious selection would result in smaller interspecific distances spread across a number of ecological traits. If natural selection takes the latter form and signal divergence inherently happens in fewer dimensions, then explosive early divergence of signals need not indicate sexual selection as the most fundamental cause in all cases. Sexual signals might appear to diverge first only because large, stereotyped signal differences are recruited by natural selection acting earlier and more cryptically on several ecological traits simultaneously. Under this hypothesis, divergence in signals and preferences is secondarily recruited (e.g., by reinforcement on secondary contact) to prevent ecologically maladaptive mismatings. This hypothetical scenario for early signal divergence due to multifarious ecological selection potentially applies to any radiation in which sexual signals appear to diverge faster than all measured ecological traits—causing evolutionary biologists to therefore invoke sexual selection, in the broad sense, as the fundamental cause. The possibility that signals might generally diverge in fewer dimensions than do traits under natural selection during ecological speciation merits some consideration, given that animal perception and preference may evolve to narrowly target a limited number of salient signal components. Currently, however, we have no empirical support for this scenario. More important, signals themselves are often found to be multidimensional (Candolin 2003; Partan and Marler 2005; Elias et al. 2006b; Hebets 2008), including electric signals (Carlson 2002; Wong and Hopkins 2007). Until relevant data become available for multiple assumptions in the above scenario, the most parsimonious explanation for the observed disparity in trait divergence rates is that sexual selection on electrical courtship signals has played a seminal role in driving the Paramormyrops species radiation.

The body of work on the neurobiology underlying mormyrid electric signals permits a broad understanding of their role in speciation. The opportunity for rapid signal evolution in mormyrids has arisen through key innovations in communication. The origin of the mormyroid 
Table 4: Difference in initial divergence rates between electric signals and each of the three ecological traits (i.e., results of the main analysis)

\begin{tabular}{|c|c|c|c|c|c|c|}
\hline Taxa and rate & $\begin{array}{c}\text { Balé Creek: electric } \\
\text { signals vs. trophic } \\
\text { ecology }\end{array}$ & $\begin{array}{l}\text { Loa Loa: electric } \\
\text { signals vs. trophic } \\
\text { ecology }\end{array}$ & $\begin{array}{c}\text { Balé Creek: electric } \\
\text { signals vs. body } \\
\text { shape }\end{array}$ & $\begin{array}{c}\text { Loa Loa: electric } \\
\text { signals vs. body } \\
\text { shape }\end{array}$ & $\begin{array}{c}\text { Balé Creek: electric } \\
\text { signals vs. body } \\
\text { size }\end{array}$ & $\begin{array}{c}\text { Loa Loa: electric } \\
\text { signals vs. body } \\
\text { size }\end{array}$ \\
\hline \multicolumn{7}{|c|}{ All mormyrids: ${ }^{a}$} \\
\hline$\beta_{\text {sig }}$ & $+1,538$ & $+1,071$ & $+1,538$ & $+1,071$ & $+1,538$ & $+1,071$ \\
\hline$\beta_{\text {iso }}$ & +180 & +121 & & & & \\
\hline$\beta_{\text {shape }}$ & & & +50 & +49 & & \\
\hline$\beta_{\text {size }}$ & & & & & +12 & +65 \\
\hline$P$ & $<.0001$ & $<.0001$ & .0195 & .0154 & $<.0001$ & $<.0001$ \\
\hline \multicolumn{7}{|c|}{ Paramormyrops only: } \\
\hline$\beta_{\mathrm{sig}}$ & $+1,538$ & $+1,100$ & $+1,538$ & $+1,100$ & $+1,538$ & $+1,100$ \\
\hline$\beta_{\text {iso }}$ & +155 & +121 & & & & \\
\hline$\beta_{\text {shape }}$ & & & +345 & +373 & & \\
\hline$\beta_{\text {size }}$ & & & & & +154 & +65 \\
\hline$P$ & $<.0001$ & $<.0001$ & $<.0001$ & .0012 & $<.0001$ & $<.0001$ \\
\hline
\end{tabular}

Note: The estimated initial rate of divergence for signals is denoted $\beta_{\text {sig }}$ the estimated initial rate of divergence for the ecological trait to which signals are compared is denoted $\beta_{\text {iso, }}, \beta_{\text {shape }}$, or $\beta_{\text {size }}$ for trophic ecology, body shape, or body size, respectively. The $P$ value for the difference between rates is shown.

a Including both morphs of the magnostipes complex.

electric organ allowed exploitation of a novel signaling modality in Africa. Subsequently, the origin and elaboration of stalks in the electrocytes composing the electric organ further enhanced opportunity for divergence in signal space within the mormyroid lineage containing Paramormyrops (Sullivan et al. 2000; Lavoué et al. 2008b). Interestingly, the mormyroid lineage lacking these electrocyte stalks (Gymnarchidae) has failed to diversify. Discussions of adaptive radiation often relate diversification to key innovations and/or the opening of new niche space (Simpson 1953; Schluter 2000; Losos and Ricklefs 2009; Parent and Crespi 2009), and our work offers a close parallel in the context of sexual selection.

While the dynamics of diversification in the Mormyridae and their close relatives within the bonytongue fishes (superorder Osteoglossomorpha) should be investigated using formal methods (Ricklefs 2007), the taxonomic pattern of species richness among bonytongue groups, by itself, shows that recent diversification has been disproportionately high in mormyrids. Among all bonytongue families, the Mormyridae have by far the highest species diversity, with 189 valid species, according to Eschmeyer (2010). This mormyrid species count is an underestimate, as it excludes a large number of recently discovered, undescribed species (Sullivan et al. 2002; Arnegard et al. 2005; Feulner et al. 2008; Lavoué et al. 2008b). Few new species have been discovered or described lately in other osteoglossomorph groups, in contrast to mormyrids (Pouyaud et al. 2003). The next most speciose family of bonytongues is the sister group to the Mormyroidea, the Notopteridae (Lavoué and Sullivan 2004), with only 10 extant species. All other osteoglossomorph families contain fewer than 10 species (Eschmeyer 2010). Within the Mormyridae, only 25 valid species are members of the Petrocephalinae. The remaining $160+$ species are found within the only other subfamily, the Mormyrinae-the lineage containing Paramormyrops. Therefore, the mormyrine subfamily of African weakly electrogenic fishes alone accounts for more than $75 \%$ of the extant species diversity across a globally distributed teleost superorder. Key innovations in electrical communication and sexual selection have very likely contributed to this apparent spike in diversification rate.

Cleanly separating mechanisms of selection causing differences in trait divergence rates is facilitated when sexual signals are decoupled from ecological traits, as they largely are in Ivindo River mormyrids. Despite this decoupling, insights from this study are still instructive for the many other animal radiations beyond mormyrid electric fish, in which sexual signals are much more intertwined with ecology. Just because two selective influences are largely independent does not mean that they have nothing to teach us about their actions and consequences when coupled to greater degrees. The Paramormyrops species flock seems to represent a rather extreme vertebrate example along the sexual selection-natural selection continuum, as well as along the trait-decoupling continuum. Understanding organismal features and aspects of the communication system that influence the position of different groups along these continuums will promote a deeper mechanistic understanding of animal species radiation in general.

The effect that extrinsic opportunity appears to have in promoting explosive signal divergence in Paramormyrops may represent a process that has occurred after other major innovations in communication during the broader radiation of animals on Earth. However, the signatures of this process may be difficult to detect because signaling traits 


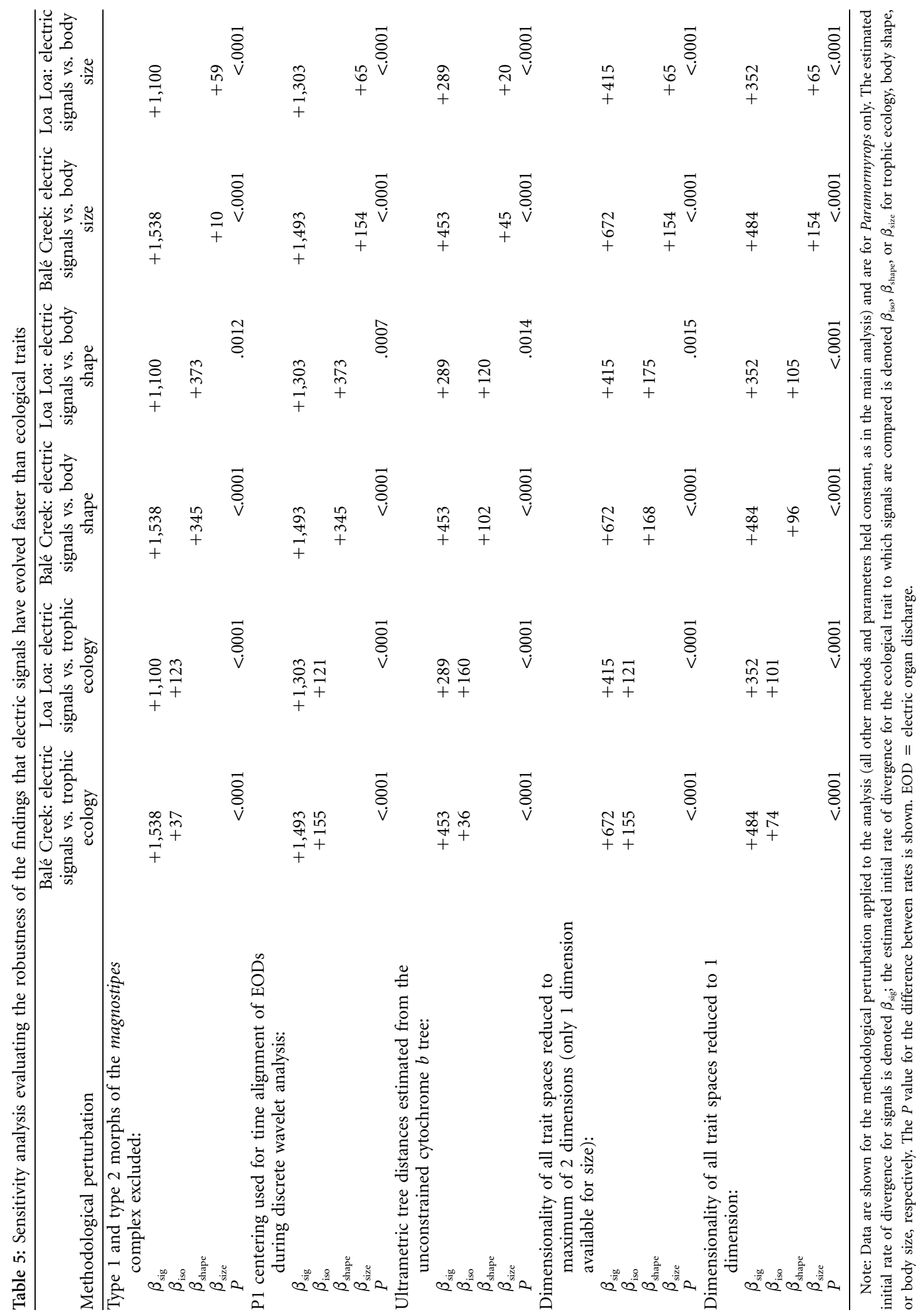

This content downloaded from 132.170.015.255 on May 07, 2019 09:22:06 AM

All use subject to University of Chicago Press Terms and Conditions (http://www.journals.uchicago.edu/t-and-c). 
are rarely captured in the fossil record. Moreover, a connection between opportunity in the signaling landscape and rapid signal divergence may also contribute to contemporary insular radiations where few competing signalers co-occur. For example, the importance of openness in "sound space" (Otte 1994) has been discussed in relation to the rapid radiation of cricket species by sexual selection on newly formed Hawaiian Islands (Mendelson and Shaw 2005). The comparative framework developed here for mormyrids could profitably be applied to comparing rates of signal and ecological trait divergence in insects, frogs, and other animal groups (Gerhardt and Huber 2002).

Our analysis provides quantitative, phylogenetically explicit evidence that sexual signal divergence outpaces divergence in several important ecological traits during a species radiation. This pattern complements many other studies in suggesting that sexual selection is a potent agent of diversification (Ritchie 2007). Mormyrid electric fishes also highlight the significance of key innovations and underexploited niches as unifying evolutionary principles applicable to species radiations driven by both natural selection and sexual selection. We have shown that a largely private signal space, made accessible by key innovations in communication, can permit the rapid divergence of courtship signals by sexual selection, which has apparently fueled mormyrid speciation. The opportunity for species radiation provided by unexploited signal space offers a conceptual parallel to the well-studied role of ecological opportunity in adaptive radiation.

\section{Acknowledgments}

Le Centre National de la Recherche Scientifique et Technologique of Gabon granted permission to collect fishes and work at the IRET field station near Makokou. We thank J. D. Mbega for providing logistical support during our fieldwork there. J. M. Moore, C. L. Peichel, D. L. Rabosky, D. Schluter, and the RoHa lab group at the University of Idaho provided helpful comments and advice during our study. DNA sequencing was conducted in the Fuller Evolutionary Biology Lab at the Cornell Laboratory of Ornithology. J. P. Friel curated our voucher specimens at the Cornell University Museum of Vertebrates and helped us make high-quality photographs of preserved specimens for morphological analysis. This research was supported by the National Geographic Society (award 7879-05 to M.E.A. and P.B.M.), the National Science Foundation (award INT-0502341 to M.E.A., award INT0321443 to P.B.M., award DEB-0919499 to L.J.H., award DEB-0614334 to W.G.R.C., and award IOS-0818305 to C.D.H.), and the National Institutes of Health (award 5R01DC6206 to C.D.H.).

\section{Literature Cited}

Allender, C. J., O. Seehausen, M. E. Knight, G. F. Turner, and N. Maclean. 2003. Divergent selection during speciation of Lake Malawi cichlid fishes inferred from parallel radiations in nuptial coloration. Proceedings of the National Academy of Sciences of the USA 100:14074-14079.

Alves-Gomes, J., and C. D. Hopkins. 1997. Molecular insights into the phylogeny of mormyriform fishes and the evolution of their electric organs. Brain, Behavior, and Evolution 49:324-351.

Arnegard, M. E., and B. A. Carlson. 2005. Electric organ discharge patterns during group hunting by a mormyrid fish. Proceedings of the Roval Society B: Biological Sciences 272:1305-1314.

Arnegard, M. E., and C. D. Hopkins. 2003. Electric signal variation among seven bluntsnouted Brienomyrus species (Teleostei: Mormyridae) from a riverine species flock in Gabon, Central Africa. Environmental Biology of Fishes 67:321-339.

Arnegard, M. E., and A. S. Kondrashov. 2004. Sympatric speciation by sexual selection alone is unlikely. Evolution 58:222-237.

Arnegard, M. E., S. M. Bogdanowicz, and C. D. Hopkins. 2005. Multiple cases of striking genetic similarity between alternate electric fish signal morphs in sympatry. Evolution 59:324-343.

Arnegard, M. E., B. S. Jackson, and C. D. Hopkins. 2006. Timedomain signal divergence and discrimination without receptor modification in sympatric morphs of electric fishes. Journal of Experimental Biology 209:2182-2198.

Arnqvist, G., M. Edvardsson, U. Friberg, and T. Nilsson. 2000. Sexual conflict promotes speciation in insects. Proceedings of the National Academy of Sciences of the USA 97:10460-10464.

Baier, B. 2008. Effect of conductivity changes on the stability of electric signal waveforms in dwarf stonebashers (Mormyridae; Pollimyrus castelnaui, P. marianne). Journal of Comparative Physiology A 194:915-919.

Barraclough, T. G., P. H. Harvey, and S. Nee. 1995. Sexual selection and taxonomic diversity in passerine birds. Proceedings of the Royal Society B: Biological Sciences 259:211-215.

Bass, A. H. 1986a. Electric organs revisited: evolution of a vertebrate communication and orientation organ. Pages 13-70 in T. H. Bullock and W. Heiligenberg, eds. Electroreception. Wiley, New York.

Bass, A. H., and C. D. Hopkins. 1983. Hormonal control of sexual differentiation: changes in electric organ discharge waveform. $\underline{\text { Sci- }}$ ence 220:971-974.

Bell, C. C., J. Bradbury, and C. J. Russell. 1976. The electric organ of a mormyrid as a current and voltage source. Journal of Comparative Physiology 110:65-88.

Blomberg, S. P., T. Garland Jr., and A. R. Ives. 2003. Testing for phylogenetic signal in comparative data: behavioral traits are more labile. Evolution 57:717-745.

Bookstein, F. L. 1986. Size and shape spaces for landmark data in two dimensions. Statistical Science 1:181-222.

- 1997. Landmark methods for forms without landmarks: morphometrics of group differences in outline shape. Medical Image Analysis 1:97-118.

Boul, K. E., W. C. Funk, C. R. Darst, D. C. Cannatella, and M. J. Ryan. 2007. Sexual selection drives speciation in an Amazonian frog. Proceedings of the Roval Society B: Biological Sciences 274: 399-406.

Bradbury, J. W., and S. L. Vehrencamp. 1998. Principles of animal communication. Sinauer, Sunderland, MA. 
Candolin, U. 2003. The use of multiple cues in mate choice. Biological Reviews 78:575-595.

Caputi, A. A., B. A. Carlson, and O. Macadar. 2005. Electric organs and their control. Pages 410-451 in T. H. Bullock, C. D. Hopkins, A. N. Popper, and R. R. Fay, eds. Electroreception. Springer, New York.

Carlson, B. A. 2002. Electric signaling behavior and the mechanisms of electric organ discharge production in mormyrid fish. Journal of Physiology Paris 96:405-419.

Cherry, L. M., S. M. Case, J. G. Kunkel, J. S. Wyles, and A. C. Wilson. 1982. Body shape metrics and organismal evolution. Evolution 36: 914-933.

Coyne, J. A., and H. A. Orr. 2004. Speciation. Sinauer, Sunderland, MA.

Crampton, W. G. R., J. K. Davis, N. R. Lovejoy, and M. Pensky. 2008. Multivariate classification of animal communication signals: a simulation-based comparison of alternative signal processing procedures using electric fishes. Journal of Physiology Paris 102:304-321.

Eldredge, N., J. N. Thompson, P. M. Brakefield, S. Gavrilets, D. Jablonski, J. B. C. Jackson, R. E. Lenski, B. S. Lieberman, M. A. McPeek, and W. Miller III. 2005. The dynamics of evolutionary stasis. Paleobiology 31(suppl.):133-145

Elias, D. O., E. A. Hebets, and R. R. Hoy. 2006a. Female preference for complex/novel signals in a spider. Behavioral Ecology 17:765771.

Elias, D. O., E. A. Hebets, R. R. Hoy, W. P. Maddison, and A. C. Mason. 2006b. Regional seismic song differences in sky island populations of the jumping spider Habronattus pugillis Griswold (Araneae, Salticidae). Journal of Arachnology 34:545-556.

Endler, J. A. 1992. Signals, signal conditions, and the direction of evolution. American Naturalist 139(suppl.):S125-S153.

Eschmeyer, W. N. 2010. Catalog of fishes. California Academy of Sciences, San Francisco. http://research.calacademy.org/ichthyology/ catalog/fishcatmain.asp.

Felsenstein, J. 1985. Phylogenies and the comparative method. American Naturalist 125:1-15.

Feulner, P. G. D., F. Kirschbaum, V. Mamonekene, V. Ketmaier, and R. Tiedemann. 2007. Adaptive radiation in African weakly electric fish (Teleostei: Mormyridae: Campylomormyrus): a combined molecular and morphological approach. Journal of Evolutionary Biology 20:403-414.

Feulner, P. G. D., F. Kirschbaum, and R. Tiedemann. 2008. Adaptive radiation in the Congo River: an ecological speciation scenario for African weakly electric fish (Teleostei; Mormyridae; Campylomormyrus). Journal of Physiology Paris 102:340-346.

Feulner, P. G. D., M. Plath, J. Engelmann, F. Kirschbaum, and R. Tiedemann. 2009a. Electrifying love: electric fish use speciesspecific discharge for mate recognition. Biology Letters 5:225-228.

Fry, B. 2006. Stable isotope ecology. Springer, New York.

Genner, M. J., G. F. Turner, S. Barker, and S. J. Hawkins. 1999. Niche segregation among Lake Malawi cichlid fishes? evidence from stable isotope signatures. Ecology Letters 2:185-190.

Gerhardt, H. C. 1999. Reproductive character displacement and other sources of selection on acoustic communication systems. Pages 515-534 in M. D. Hauser and M. Konishi, eds. The design of animal communication. MIT Press, Cambridge, MA.

Gerhardt, H. C., and F. Huber. 2002. Acoustic communication in insects and anurans: common problems and diverse solutions. University of Chicago Press, Chicago.
Gingerich, P. D. 1993. Quantification and comparison of evolutionary rates. American Journal of Science 293-A:453-478.

Grant, P. R., and B. R. Grant. 2008. How and why species multiply: the radiation of Darwin's finches. Princeton University Press, Princeton, NJ.

Green, W. D. K. 1996. The thin-plate spline and images with curving features. Pages 79-87 in K. V. Mardia, C. A. Gill, and I. L. Dryden, eds. Image fusion and shape variability. University of Leeds Press, Leeds.

Hanika, S., and B. Kramer. 2000. Electrosensory prey detection in the African sharptooth catfish, Clarias gariepinus (Clariidae), of the weakly electric mormyrid fish, the bulldog (Marcusenius macrolepidotus). Behavioral Ecology and Sociobiology 48:218-228.

Hebets, E. A. 2008. Seismic signal dominance in the multimodal courtship display of the wolf spider Schizocosa stridulans Stratton 1991. Behavioral Ecology 19:1250-1257.

Helland, I. P., C. Harrod, J. Freyhof, and T. Mehner. 2008. Coexistence of a pair of pelagic planktivorous coregonid fishes. Evolutionary Ecology Research 10:373-390.

Hendry, A. P., and M. T. Kinnison. 1999. The pace of modern life: measuring rates of contemporary microevolution. Evolution 53: $1637-1653$

Herfeld, S., and P. Moller. 1998. Effects of $17 \alpha$-methyltestosterone on sexually dimorphic characters in the weakly discharging electric fish, Brienomyrus niger (Günther, 1866) (Mormyridae): electric organ discharge, ventral body wall indentation, and anal-fin ray bone expansion. Hormones and Behavior 34:303-319.

Hoeinghaus, D. J., and S. C. Zeug. 2008. Can stable isotope ratios provide for community-wide measures of trophic structure? comment. Ecology 89:2353-2357.

Hopkins, C. D. 1973. Lightning as background noise for communication among electric fish. Nature 242:268-270.

1980. Evolution of electric communication channels of mormyrids. Behavioral Ecology and Sociobiology 7:1-13.

. 1986. Behavior of Mormyridae. Pages 527-576 in T. H. Bullock and W. Heiligenberg, eds. Electroreception. Wiley, New York.

1999. Design features for electric communication. Journal of Experimental Biology 202:1217-1228.

. 2010. Electroreception. Pages 384-387 in E. B. Goldstein, ed. Encyclopedia of perception. Sage, Thousand Oaks, CA.

Hopkins, C. D., and A. H. Bass. 1981. Temporal coding of species recognition signals in an electric fish. Science 212:85-87.

Hopkins, C. D., S. Lavoué, and J. P. Sullivan. 2007. Mormyridae. Pages 219-334 in M. L. J. Stiassny, G. G. Teugels, and C. D. Hopkins, eds. Poissons d'eaux douces et saumâtres de basse Guinée, ouest de l'Afrique centrale (The fresh and brackish water fishes of Lower Guinea, west-central Africa). IRD, Paris.

Hubbell, S. P. 2001. The unified neutral theory of biodiversity and biogeography. Princeton University Press, Princeton, NJ.

Kawasaki, M. 2005. Physiology of tuberous electrosensory systems. Pages 154-194 in T. H. Bullock, C. D. Hopkins, A. N. Popper, and R. R. Fay, eds. Electroreception. Springer, New York.

Kazancioğlu, E., T. J. Near, H. Reinhold, and P. C. Wainwright. 2009. Influence of sexual selection and feeding functional morphology on diversification rate of parrotfishes (Scaridae). Proceedings of the Roval Society B: Biological Sciences 276:3439-3446.

Kingston, T., and S. J. Rossiter. 2004. Harmonic-hopping in Wallacea's bats. Nature 429:654-657.

Kirkpatrick, M., and S. L. Nuismer. 2004. Sexual selection can con- 
strain sympatric speciation. Proceedings of the Royal Society B: Biological Sciences 271:687-693.

Lavoué, S., and J. P. Sullivan. 2004. Simultaneous analysis of five molecular markers provides a well-supported phylogenetic hypothesis for the living bony-tongue fishes (Osteoglossomorpha: Teleostei). Molecular Phvlogenetics and Evolution 33:171-185.

Lavoué, S., R. Bigorne, G. Lecointre, and J. F. Agnèse. 2000. Phylogenetic relationships of mormyrid electric fishes (Mormyridae, Teleostei) inferred from cytochrome $b$ sequences. Molecular Phvlogenetics and Evolution 14:1-10.

Lavoué, S., J. P. Sullivan, and C. D. Hopkins. 2003. Phylogenetic utility of the first two introns of the S7 ribosomal protein gene in African electric fishes (Mormyroidea: Teleostei) and congruence with other molecular markers. Biological Journal of the Linnean Society 78:273-292.

Lavoué, S., C. D. Hopkins, and A. Kamdem Toham. 2004. The Petrocephalus (Pisces, Osteoglossomorpha, Mormyridae) of Gabon, Central Africa, with the description of a new species. Zoosystema 26:511-535.

Lavoué, S., J. P. Sullivan, M. E. Arnegard, and C. D. Hopkins. 2008 a. Differentiation of morphology, genetics and electric signals in a region of sympatry between sister species of African electric fish (Mormyridae). Journal of Evolutionary Biology 21:1030-1045.

Lavoué, S., M. E. Arnegard, J. P. Sullivan, and C. D. Hopkins. $2008 b$. Petrocephalus of Odzala offer insights into evolutionary patterns of signal diversification in the Mormyridae, a family of weakly electrogenic fishes from Africa. Journal of Physiology Paris 102: 322-339.

Lerman, A. 1965. On rates of evolution of unit characters and character complexes. Evolution 19:16-25.

Losos, J. B. 2009. Lizards in an evolutionary tree: ecology and adaptive radiation of anoles. University of California Press, Berkeley.

Losos, J. B., and R. E. Ricklefs. 2009. Adaptation and diversification on islands. Nature 457:830-836.

Losos, J. B., T. R. Jackman, A. Larson, K. de Queiroz, and L. Rodríguez-Schettino. 1998. Contingency and determinism in replicated adaptive radiations of island lizards. Science 279:2115-2118.

Lovette, I. J., E. Bermingham, and R. E. Ricklefs. 2002. Clade-specific morphological diversification and adaptive radiation in Hawaiian songbirds. Proceedings of the Roval Societv B: Biological Sciences 269:37-42.

MacArthur, R. H. 1958. Population ecology of some warblers of northeastern coniferous forests. Ecology 39:599-619.

Machnik, P., and B. Kramer. 2008. Female choice by electric pulse duration: attractiveness of the males' communication signal assessed by female bulldog fish, Marcusenius pongolensis (Mormyridae, Teleostei). Journal of Experimental Biology 211:1969-1977.

Mahalanobis, P. C. 1936. On the generalized distance in statistics. Proceedings of the National Institute of Sciences of India 2:49-55.

Mallat, S. 1999. A wavelet tour of signal processing. Academic Press, San Diego, CA.

Marrero, C., and K. O. Winemiller. 1993. Tube-snouted gymnotiform and mormyriform fishes: convergence of a specialized foraging mode in teleosts. Environmental Biology of Fishes 38:299-309.

Masta, S. E., and W. P. Maddison. 2002. Sexual selection driving diversification in jumping spiders. Proceedings of the National Academy of Sciences of the USA 99:4442-4447.

Matthews, B., K. B. Marchinko, D. I. Bolnick, and A. Mazumder. 2010. Specialization of trophic position and habitat use by sticklebacks in an adaptive radiation. Ecology 91:1025-1034.
McClure, M. M., P. B. McIntyre, and A. R. McCune. 2006. Notes on the natural diet and habitat of eight danionin fishes, including the zebrafish Danio rerio. Journal of Fish Biology 68:1-18.

McIntyre, P. B., and A. S. Flecker. 2006. Rapid turnover of tissue nitrogen of primary consumers in tropical freshwaters. Oecologia (Berlin) 148:12-21.

McKinnon, J. S., S. Mori, B. K. Blackman, L. David, D. M. Kingsley, L. Jamieson, J. Chou, and D. Schluter. 2004. Evidence for ecology's role in speciation. Nature 429:294-298.

Mendelson, T. C., and K. L. Shaw. 2005. Rapid speciation in an arthropod. Nature 433:375-376.

Moller, P. 1995. Electric fishes: history and behavior. Chapman \& Hall, New York.

Neter, J., and W. Wasserman. 1974. Applied linear statistical models: regression, analysis of variance, and experimental designs. Irwin, Homewood, IL.

Nosil, P., and L. Harmon. 2009. Niche dimensionality and ecological speciation. Pages 127-154 in R. K. Butlin, J. R. Bridle, and D. Schluter, eds. Speciation and patterns of diversity. Cambridge University Press, Cambridge.

Otte, D. 1994. The crickets of Hawaii: origin, systematics and evolution. Orthopterists' Society/Academy of Natural Sciences of Philadelphia, Philadelphia.

Parent, C. E., and B. J. Crespi. 2009. Ecological opportunity in adaptive radiation of Galápagos endemic land snails. American Naturalist 174:898-905.

Partan, S. R., and P. Marler. 2005. Issues in the classification of multimodal communication signals. American Naturalist 166:231-245.

Pezzanite, B., and P. Moller. 1998. A sexually dimorphic basal analfin ray expansion in the weakly discharging electric fish Gnathonemus petersii. Journal of Fish Biology 53:638-644.

Podos, J. 2001. Correlated evolution of morphology and vocal signal structure in Darwin's finches. Nature 409:185-188.

Podos, J., and A. P. Hendry. 2006. The biomechanics of ecological speciation. Pages 301-321 in A. Herrel, T. Speck, and N. P. Rowe, eds. Ecology and biomechanics: a mechanical approach to the ecology of animals and plants. CRC, Boca Raton, FL.

Post, D. M. 2002. Using stable isotopes to estimate trophic position: models, methods, and assumptions. Ecology 83:703-718.

Pouyaud, L., Sudarto, and G. G. Teugels. 2003. The different colour varieties of the Asian arowana Scleropages formosus (Osteoglossidae) are distinct species: morphologic and genetic evidences. Cybium 27:287-305.

Price, J. J., N. R. Friedman, and K. E. Omland. 2007. Song and plumage evolution in the New World orioles (Icterus) show similar lability and convergence in patterns. Evolution 61:850-863.

Price, T. 1998. Sexual selection and natural selection in bird speciation. Philosophical Transactions of the Roval Societv B: Biological Sciences 353:251-260.

R Core Development Team. 2009. R, version 2.9.0. R Foundation for Statistical Computing, Vienna. http://www.r-project.org/.

Ricklefs, R. E. 2007. Estimating diversification rates from phylogenetic information. Trends in Ecology \& Evolution 22:601-610.

Ritchie, M. G. 2007. Sexual selection and speciation. Annual Review of Ecology, Evolution, and Systematics 38:79-102.

Rohlf, F. J., and D. Slice. 1990. Extensions of the Procrustes method for the optimal superimposition of landmarks. Systematic Zoology 39:40-59.

Rundell, R. J., and T. D. Price. 2009. Adaptive radiation, nonadaptive 
radiation, ecological speciation and nonecological speciation. Trends in Ecology \& Evolution 24:394-399.

Rundle, H. D., L. N. Nagel, J. W. Boughman, and D. Schluter. 2000. Natural selection and parallel speciation in sympatric sticklebacks. Science 287:306-308.

Sanderson, M. J. 2003. r8s: inferring absolute rates of molecular evolution and divergence times in the absence of a molecular clock. Bioinformatics 19:301-302.

Schluter, D. 2000. The ecology of adaptive radiation. Oxford University Press, New York.

Schoener, T. W. 1989. The ecological niche. Pages 79-113 in J. M. Cherrett, ed. Ecological concepts: the contribution of ecology to an understanding of the natural world. Blackwell Scientific, Oxford.

Seehausen, O. 2009. Progressive levels of trait divergence along a "speciation transect" in the Lake Victoria cichlid fish Pundamilia. Pages 155-176 in R. K. Butlin, J. R. Bridle, and D. Schluter, eds. Speciation and patterns of diversity. Cambridge University Press, Cambridge.

Seehausen, O., Y. Terai, I. S. Magalhaes, K. L. Carleton, H. D. J. Mrosso, R. Miyagi, I. van der Sluijs, et al. 2008. Speciation through sensory drive in cichlid fish. Nature 455:620-626.

Servedio, M. R., and M. A. F. Noor. 2003. The role of reinforcement in speciation: theory and data. Annual Review of Ecology, Evolution, and Systematics 34:339-364.

Simpson, G. G. 1953. The major features of evolution. Columbia University Press, New York.

Stoddard, P. K. 1999. Predation enhances complexity in the evolution of electric fish signals. Nature 400:254-256.

Streelman, J. T., and P. D. Danley. 2003. The stages of vertebrate evolutionary radiation. Trends in Ecology \& Evolution 18:126-131.

Sullivan, J. P., and C. D. Hopkins. 2004. A new Stomatorhinus (Osteoglossomorpha: Mormyridae) from the Ivindo River, Gabon, west central Africa. Zootaxa 847:1-23.

Sullivan, J. P., S. Lavoué, and C. D. Hopkins. 2000. Molecular systematics of the African electric fishes (Mormyroidea: Teleostei) and a model for the evolution of their electric organs. Journal of Experimental Biology 203:665-683.

2002. Discovery and phylogenetic analysis of a riverine species flock of African electric fishes (Mormyridae: Teleostei). Evolution 56:597-616.

Sullivan, J. P., S. Lavoué, M. E. Arnegard, and C. D. Hopkins. 2004. AFLPs resolve phylogeny and reveal mitochondrial introgression within a species flock of African electric fish (Mormyroidea: Teleostei). Evolution 58:825-841.

von der Emde, G., S. Schwarz, L. Gomez, R. Budelli, and K. Grant. 1998. Electric fish measure distance in the dark. Nature 395:890894.

Winemiller, K. O., and A. Adite. 1997. Convergent evolution of weakly electric fishes from floodplain habitats in Africa and South America. Environmental Biology of Fishes 49:175-186.

Wong, R. Y., and C. D. Hopkins. 2007. Electrical and behavioral courtship displays in the mormyrid fish Brienomyrus brachyistius. Journal of Experimental Biology 210:2244-2252.

Xu-Friedman, M. A., and C. D. Hopkins. 1999. Central mechanisms of temporal analysis in the knollenorgan pathway of mormyrid electric fish. Journal of Experimental Biology 202:1311-1318.

Yang, Z. 1994. Maximum likelihood phylogenetic estimation from DNA sequences with variable rates over sites: approximate methods. Journal of Molecular Evolution 39:306-314.

Zakon, H. H. 1988. The electroreceptors: diversity in structure and function. Pages 813-850 in J. Atema, R. R. Fay, A. N. Popper, and W. N. Tavolga, eds. Sensory biology of aquatic animals. Springer, New York.

Zwickl, D. J. 2006. Genetic algorithm approaches for the phylogenetic analysis of large biological sequence datasets under the maximum likelihood criterion. $\mathrm{PhD}$ diss. University of Texas, Austin. http://www.zo.utexas.edu/faculty/antisense/garli/Garli.html.

Associate Editor: Allen J. Moore Editor: Mark A. McPeek

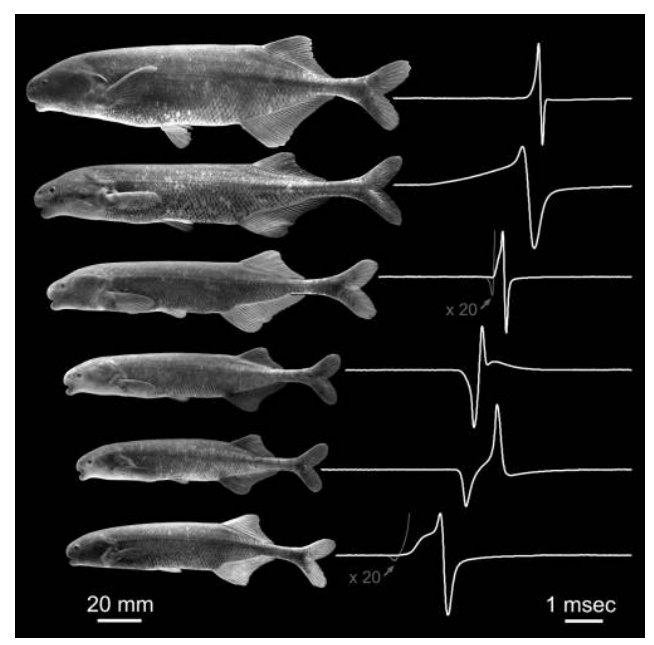

Species and morphs co-occurring in the Okano River at the abandoned village Na, near Mitzig, are shown with their electric signals. Top to bottom, Paramormyrops sp. OKA, Paramormyrops curvifrons, Paramormyrops sp. SZA, type 1 morph (magnostipes complex), type 3 morph (magnostipes complex), and Paramormyrops kingsleyae. Image by M. E. Arnegard and D. T. Reid. 